\title{
Semiconducting quantum dots: Modification and applications in biomedical science
}

\author{
Lude Wang ${ }^{1}$, Duo $\mathrm{Xu}^{2}$, Jie $\mathrm{Gao}^{2}$, Xiang $\mathrm{Chen}^{2^{*}}$, Yanhong Duo ${ }^{1,3^{*}}$ and Han Zhang ${ }^{1 *}$
}

\begin{abstract}
Semiconductor quantum dots (SQDs) have received much attention due to their high quantum yield (QY), tunable emission spectrum, and excellent photostability. These unique optical properties endow SQDs with excellent biomedical application prospects, including biomedical imaging, drug delivery, clinical diagnosis, photodynamic therapy, DNA hybridization, and RNA profiling. This review introduces the classification of QDs and provides a brief description of the characteristics of QDs under each classification. Taking the type II B-VI A QDs as an example, inorganic and organic modification methods, and the corresponding advantages and disadvantages are summarized and discussed. Controlled modification approaches make them exhibit different functions in the bioimaging and drug delivery fields. The typical or classic instances are also listed to present the highlights of the applications of SQDs in the biomedical field. Based on these, this review raises a variety of possible challenges and perspectives of SQDs in biomedical applications in the future.
\end{abstract}

Keywords: semiconducting quantum dots, modification, imaging, drug delivery, biomaterials

\section{INTRODUCTION}

Semiconductor quantum dots (SQDs) have attracted great attention in recent decades, due to their unique optoelectronic properties [1], such as strong absorption, size-dependent photo-luminescent emission, high quantum yield (QY), and high optical stability. Different types of QDs exhibit functional characteristics in a variety of fields, including sensing [2], optoelectronic devices [3], biomedicine [4], and energy [5].

The exploration of SQDs has always been full of chal- lenges. For example, most of the early QDs investigated were oil-soluble [6] and easy to agglomerate after drying, resulting in fluorescence quenching. Thus, there are considerable application difficulties in the biological fields. With the advent of water-soluble QDs [7], QDs could exhibit stable illumination in biological samples. Although traditional SQDs have excellent optical properties, the biosafety problems due to the presence of heavy metals such as cadmium containing QDs, cannot be ignored [8]. The emergence of QDs with high biocompatibility and safety, such as carbon QDs (CQDs), graphene QDs, silicon QDs [9], and black phosphorus QDs (BPQDs) [10], has accelerated the application of QDs in the biomedical field. QDs can simultaneously achieve diversified applications in the same area, such as BPQDsbased [11,12] multifunctional nanoplatforms for bioimaging, photothermal therapy, and photodynamic therapy. However, although technical breakthroughs in the research of QDs have been widely demonstrated, there are still many gaps in basic research. A variety of intrinsic problems, such as the luminescence mechanism and the surface state of QDs, are still inconclusive. These problems directly affect the precise modification, controllable modification, service mechanism, and performance improvement of QDs. Consequently, many QDsrelevant studies have achieved unique phenomena, but they were unable to provide a definitive theoretical explanation for the experimental results.

Although there are many unsolvable uncertainties in the research of QDs, they can still have more application values based on existing investigations. We provide a brief summary of the characteristics and application directions of different types of QDs in the section of

\footnotetext{
${ }^{1}$ International Collaborative Laboratory of 2D Materials for Optoelectronics Science and Technology of Ministry of Education, Institute of Microscale Optoelectronics, Shenzhen University, Shenzhen 518060, China

${ }^{2}$ Institute of Optoelectronics \& Nanomaterials, MIIT Key Laboratory of Advanced Display Materials and Devices, School of Materials Science and Engineering, Nanjing University of Science and Technology, Nanjing 210094, China

${ }^{3}$ Department of Microbiology, Tumor and Cell Biology, Karolinska Institute, Stockholm 17177, Sweden

* Correspondence authors (emails: hzhang@szu.edu.cn (Zhang H); xiangchen@njust.edu.cn (Chen X); yanhong.duo@ki.se (Duo Y))
} 
CLASSIFICATION AND APPLICATION. Among these QDs, type II B-VI A QDs were selected as detailed introduction objects in the modification approaches (section of MODIFICATIONS). Based on the understanding of current modification methods for QDs, the section of BIOMEDICAL APPLICATIONS reviews the application of functionalized SQDs in bioimaging and drug delivery. The highlights and existing problems in related research are summarized and the prospects are presented in each section.

\section{CLASSIFICATION AND APPLICATION}

The concept of QDs was put forth in the 1990s [13]. In general, QDs are defined as nanocrystals with a particle size of $10 \mathrm{~nm}$ in three space dimensions. Strictly speaking, QDs are a kind of nanocrystals less than or equal to their own exciton Bohr radius in three space dimensions. According to the elemental composition, QDs can be classified as shown in Table 1.

ZnTe [14], ZnSe [15], ZnS [16], ZnO [17], CdTe [18], CdSe [19], CdS [20], HgTe [21], HgSe [22], and HgS [23] QDs are type II B-VI A QDs. The SQDs have attracted broad attention in the sensing [24], imaging [25], and biomedical [26] fields, because of their adjustable and robust fluorescence emission [27]. Chemical modification, doping [28], and core/shell technology [29] for SQDs have been developed and further adapted to practical applications. However, the biotoxicity, solubility, and light scintillation properties have been still criticized.

Type III A-V A QDs, especially InP QDs [30], usually present more stable optical properties than those of type II B-VI A QDs, because the characteristics of chemical bonds within these materials mostly appear as covalent bonds. However, this type of QDs has to overcome the problem of low QY by coating other materials with a wider energy gap, such as in $\mathrm{InP} / \mathrm{ZnS}$ [31] and $\mathrm{InP} / \mathrm{ZnS}$ QDs [32]. Type IV A-VI A QDs including PbS [33] and $\mathrm{PbSe}$ [34] QDs have smaller energy gaps. For this reason, their fluorescent emission region is mainly located in the near-infrared and mid-infrared spectral ranges. This kind of QDs can make use the most of visible light via multiple exciton effects, which are usually applied in the solar cell field [35].

In 2004, CQDs were officially named and reported to be intensely photoluminescent both in solution and solid via simple surface passivation [36]. Since then, CQDs are well known as the type IV A QDs, because of their excellent physicochemical properties, fluorescence stability, and biocompatibility. Graphene QDs of this type date back to the year of 2008 [37]. Graphene and graphene-
Table 1 The classification of QDs

\begin{tabular}{|c|c|}
\hline Type & Example \\
\hline I B-VI A & $\mathrm{Cu}_{2} \mathrm{~S}$ \\
\hline I B-VII A & $\mathrm{AgBr}$ \\
\hline II B-VI A & $\begin{array}{c}\text { ZnTe, ZnSe, ZnS, ZnO, CdS, CdSe, CdTe, } \\
\text { HgTe, HgSe, HgS }\end{array}$ \\
\hline III A-V A & $\begin{array}{c}\text { AlSb, AlAs, AlP, GaSb, GaAs ,InGaAs, InAs, } \\
\text { InP, InN }\end{array}$ \\
\hline IV A-VI A & $\mathrm{PbS}, \mathrm{PbSe}, \mathrm{PbTe}$ \\
\hline IV A & C, Si, Graphene \\
\hline V A & Black P \\
\hline I B-III A-VI A & $\mathrm{CuInS}_{2}, \mathrm{CuInSe}_{2}, \mathrm{AgInS}_{2}$ \\
\hline Pdots & Semiconducting polymer dots \\
\hline TMDCs & $\mathrm{TiS}_{2}, \mathrm{TiSe}_{2}, \mathrm{TaS}_{2}, \mathrm{MoS}_{2}, \mathrm{MoSe}_{2}, \mathrm{WS}_{2}, \mathrm{WSe}{ }_{2}, \mathrm{ReS}_{2}$ \\
\hline MXene & $\begin{array}{c}\mathrm{M}_{n+1} \mathrm{X}_{n} \mathrm{Tz}(\mathrm{M}=\text { transition metals; } \mathrm{X}=\mathrm{C} \text { and/or } \mathrm{N} \text {; } \\
\left.n=1-3 ; \mathrm{Tz}=\mathrm{F}^{-}, \mathrm{O}^{2-} \text { and } \mathrm{OH}^{-} \text {etc. }\right)\end{array}$ \\
\hline Perovskite & $\operatorname{MPbX}_{3}\left(\mathrm{M}=\mathrm{Cs}\right.$ or $\mathrm{CH}_{3} \mathrm{NH}_{3} ; \mathrm{X}=\mathrm{Cl}, \mathrm{Br}$ or $\left.\mathrm{I}\right)$ \\
\hline
\end{tabular}

based composite materials [38] have been widely used in the field of optics [39] and devices [40] due to their unique properties. However, the fluorescence lifetime of QDs is usually very short, and the fluorescent signal is easily interfered by biological background fluorescence.

BPQDs have emerged in recent years [41,42]. We presented a gentle top-down method to prepare BPQDs in solution in 2015 [43]. In the following year, a solvothermal method to synthesize BPQDs was reported, and the nonlinear optical properties of BPQDs were revealed for the first time [44]. BPQDs have been successfully applied to ultrafast laser technology $[45,46]$. Other materials, such as antimonene [47,48] and bismuthene $[48,49]$, have also attracted the attention of researchers.

Ternary I B-III A-VI A QDs, such as CuInS 2 , CuInSe, and $\mathrm{AgInS}_{2}$ QDs, usually possess tunable bandgaps. Their fluorescence can be continuously adjusted from the red to the near-infrared region [50]. Due to their outstanding optical properties, QDs are applied in many fields, including biosensing, biomedical imaging [51], solar cells [52], and photovoltaic devices [53]. More importantly, the long fluorescence lifetime and low biological toxicity provide an absolute advantage for using QDs in the biological systems. After being further synthesized into core/shell structures, QDs can realize in vivo whole animal fluorescence imaging [54].

Semiconductor polymer QDs (Pdots) generally refer to a portion of semiconductor polymer nanoparticles that is equivalent in size $(<20$ to $30 \mathrm{~nm})$ to inorganic semiconductor QDs. Pdots with advantages such as small size, high brightness, fast radiation transition rate, good light 
stability, and low biological toxicity, are very suitable for bioimaging [55], sensing [56], and oncotherapy [57].

Transition metal dichalcogenide (TMDC) QDs are also a class of materials with multifunctional properties. One such example is molybdenum disulfide $\left(\mathrm{MoS}_{2}\right)$ QDs. The QDs are a type of transition metal disulfide nanomaterial with a unique two-dimensional structure similar to graphene. It has an adjustable emission spectrum, high QY, and is easily functionalized. The good biocompatibility makes TMDC QDs widely used as catalysts [58], fluorescent probes [59], biosensors [60] and tumor treatment platforms [61].

There is an important emerging material named MXene dots derived from MXene sheets. Compared with sheets, the advantage of QDs is their ultra-small size and fluorescence properties, which make them promising candidate materials in biomedical $[62,63]$, bioimaging [64], biosensing [65], catalysis, [66] and optical [67,68] fields. MXene QDs are bio-friendly materials rich in surface functional groups. They may be assembled with other functional materials to produce applied materials.

In recent years, inorganic perovskite QDs (IPQDs) have gradually emerged in the fields of light-emitting diodes (LED) [69], photo-detectors [70], QD lasers [71], and solar cells [72]. The room-temperature synthesis, superior photo-luminescence, underlying origins, and potentials in lighting and displays have been reported [73]. For better efficiency and stability, coated IPQDs have been prepared and used in white LEDs [74].

We did not introduce all QDs, such as $\mathrm{Cu}_{2} \mathrm{~S}$ [75] and $\mathrm{AgBr}$ [76] QDs, listed in Table 1. As summarized above, different types of QDs have unique highlights and advantages. Once QDs are put into practical applications, whether for forming core/shell materials or doping with other elements, further optimization of the QDs is inevitable. Among various applications based on QDs, biomedicine is considered the most directly related research field to humans. If QDs are applied in biomedical fields, fluorescence lifetime, optical stability in aqueous solution and biocompatibility of the QDs would become the primary considerations.

\section{MODIFICATIONS}

In terms of optical performance, it is necessary to control the defect states and reduce the carrier trap to significantly increase luminous efficiency and stability. If SQDs are to be employed for biological applications, more requirements, including water solubility, biocompatibility, non-specific cellular uptake [77], active targeting [78], and long fluorescence lifetime, need to be considered. Consequently, surface modification becomes very compulsory to optimize the performance of SQDs. There is an instance [79] (Fig. 1) that shows the effect of simple surface modification on the stability of ZnS-coated CdSe QDs. QDs modified with -OH show improvement in stability and dispersion within hypertonic conditions. However, all QDs are stable in nonelectrolyte solutions. Under weak alkaline conditions, all modified QDs remain stable for $30 \mathrm{~min}$. However, only amine groups-modified QDs are stable in acidic conditions. The results provide references for further surface modification of QDs for applications in biomedical fields.

\section{Organic modification}

The organic modification of SQDs refers to organic ligands [80], organic polymers [81], proteins, and other
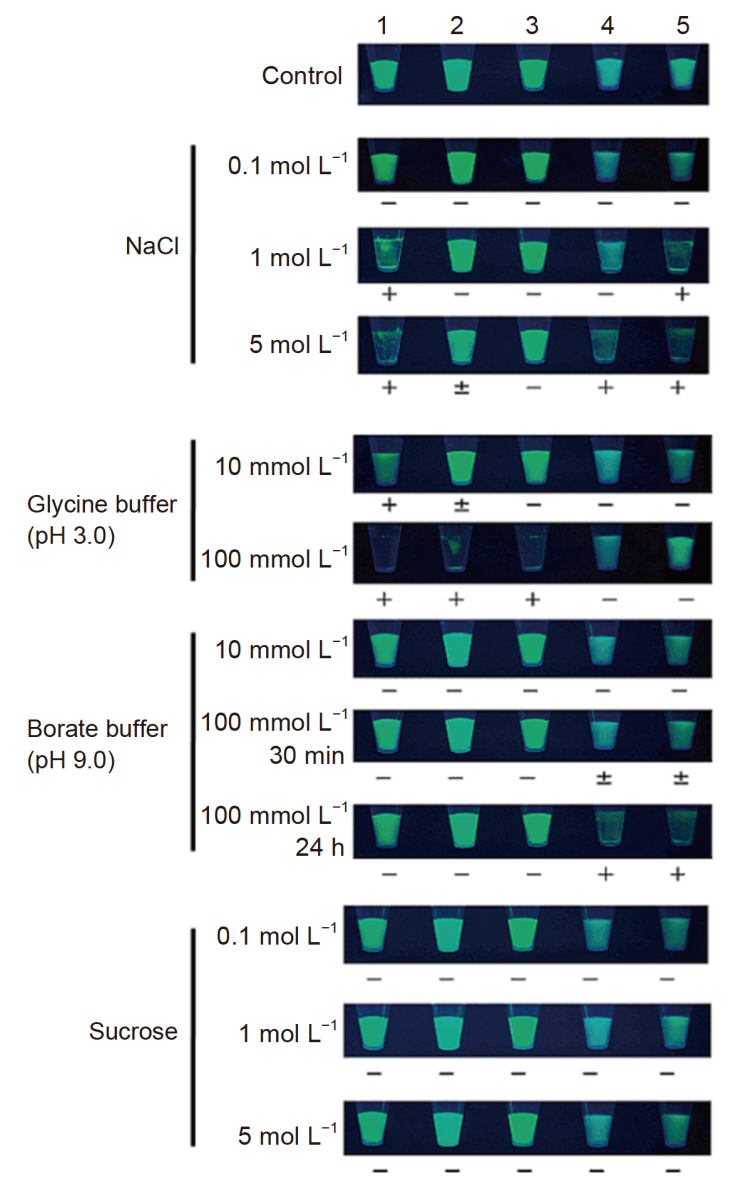

Figure 1 Physical and chemical stabilities of different modified QDs in buffers. The samples were excited at a $365-\mathrm{nm}$ wavelength. The QDs from 1 to 5 are modified by $-\mathrm{COOH},-\mathrm{OH} / \mathrm{COOH},-\mathrm{OH},-\mathrm{NH}_{2} / \mathrm{OH}$ and $-\mathrm{NH}_{2}$, respectively. The symbols,,+- and \pm , stand for aggregated, not aggregated and partially aggregated, respectively. Reprinted with permission from Ref. [79], Copyright 2004, American Chemical Society. 
organics modifiers. Organic ligand modification can optimize some characteristics of SQDs. The trapping states on the surface of SQDs, including electron traps and hole traps, cannot be simultaneously passivated by organic ligands. Besides, water molecules, oxygen and illumination can easily cause erosion and degradation of the organic ligands on the surface of SQDs. Other organic modification approaches have other problems. After surface modification with tert-butyl- $\mathrm{N}$-(2-mercaptoethyl)-carbamate, CdSe QDs showed a strong fluorescent emission with several hundred nanoseconds of fluorescence lifetimes. Unfortunately, these SQDs can only be used in the aerated methanolic solution [82]. It is reported that the surface properties decide the cytotoxicity of QDs [83]. Modification of CdSe QDs with sodium dodecyl sulfate decreased the cytotoxicity, which became useless as the incubation time and concentrations of the modifier increased. Water-soluble CdSe QDs modified with polymer exhibited strong yellow fluorescence emission that was observed both in vivo and in vitro. The QDs remained stable in aqueous solution over 30 days, suggesting the potential for bio-labeling and diagnostic purposes [84]. Even so, the average size of the modified SQDs was around $150 \mathrm{~nm}$, which is too large to enter cells via endocytosis. Modified SQDs depend on active transport to reach the inside of cells. Cell recognition is inevitable, which reduces the efficiency of the SQDs. Besides, with increase in particle size, cell viability decreases [85].

\section{Inorganic modification}

Doping with metal ions and the formation of a core/shell structure can be classified as inorganic modifications. For optimal performance, elements such as $\mathrm{Co}^{2+}, \mathrm{Ni}^{2+}[86]$, $\mathrm{Mn}^{2+}[87]$, and $\mathrm{Cu}^{2+}[88]$ are doped into SQDs to improve their intrinsic properties. CdSe/ZnS QDs were synthesized and characterized as early as 1997 [89]. After that, core/shell SQDs emerged as a new trend. The core/shell SQDs are divided into three categories. In type-I QDs, such as CdSe/ZnS QDs [90], the energy levels of the conduction band and the valence band of the shell materials are both higher than that of the core materials. The type-I approach is adopted to increase stability against photobleaching and fluorescence QY via improving surface passivation [91]. In type II, the energy level of the conduction or valence band of the shell materials is greater than that of the core materials, for instance, in $\mathrm{CdTe} / \mathrm{CdSe}$ [92] and CdSe/ZnTe QDs [93]. The emission wavelength of SQDs will show a substantial redshift, and it is possible to shift to the near-infrared region by ad- justing the thickness of the shell. In reverse type I, the bandgap of the core is greater than that of the shell, for example, in CdS/CdSe [94] and ZnSe/CdSe QDs [95]. Typically, the second and third types of core/shell SQDs need to be coated again to obtain a broader bandgap of the shell, and multiple shell structures will improve the optical properties, including enhancing the photostability, increasing the luminous efficiency, and restraining photobleaching.

The above advantages of core/shell SQDs mainly focus on the improvements in optical performance. The core/ shell structure also facilitates the applications of SQDs in biological systems. The concentrations of $\mathrm{Cd}^{2+}$ on the surface of mercaptopropionic acid (MPA)-coated CdS and CdSe/ZnS QDs were further investigated to compare the differences in cytotoxicity effects between organic and core/shell modifications [96]. The CdSe/ZnS QDs started to release $\mathrm{Cd}^{2+}$, causing the poisoning of fibroblasts cells at a concentration of $5.9 \pm 1.3 \mu \mathrm{mol} \mathrm{L}{ }^{-1}$. However, the concentration of mercaptopropionic acid-coated CdS needed to release $\mathrm{Cd}^{2+}$ was as low as $0.65 \pm 1.2 \mu \mathrm{mol} \mathrm{L}{ }^{-1}$. The core/shell SQDs have certain advantages in reducing biological toxicity. With the protection of the shell, SQDs become relatively safe and can be used in the biological systems. The CdTe/ZnSe core/shell QDs have been prepared to directly detect DNAs in the extracts of human cancer and normal cells. They were shown to be highly efficient even at an extremely low concentration of DNA [97]. To promote the practical applications, fast and large-scale preparation of core/shell QDs has also been studied. The "flash" synthesis method of CdSe/CdS core/ shell QDs has been successfully developed. No more than $3 \mathrm{~min}$ is needed to grow a thick shell up to $6.7 \mathrm{~nm}$ [98]. Water-soluble AgInSe $2 / \mathrm{ZnS}$ and $\mathrm{CuInSe}_{2} / \mathrm{ZnS}$ core/shell QDs on a multigram scale have been prepared using thioglycolic acid and gelatin as the dual stabilizers in an electric pressure cooker as the reaction vessel [99]. Core/ shell SQDs can also be designed to reduce signal interference from bioluminescence via near-infrared emissions. Water-soluble CdSeTe/ZnS core-shell QDs protected by 2 -(dimethylamino)ethanthiol were synthesized and incorporated into a chitosan film to form SQDs/chitosan films. Electrodes modified with SQDs/ chitosan films have been applied to detect concentrations of cholesterol in biological samples [100].

For application, SQDs need to be modified by many functional groups. Therefore, some surface modifications are considered to connect SQDs and functional groups. Fig. 2a shows water-soluble silica-coated CdSe/ZnS QDs [101]. The silanized QDs not only maintained the optical 
a

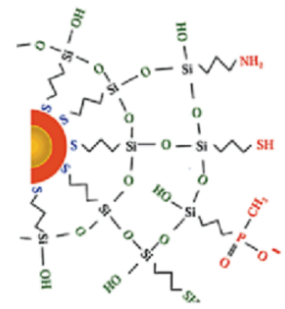

b

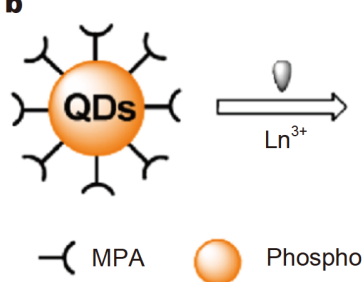

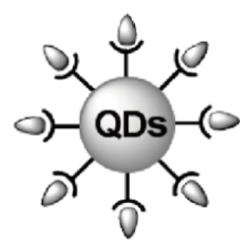

Phosphorescent QDs

c

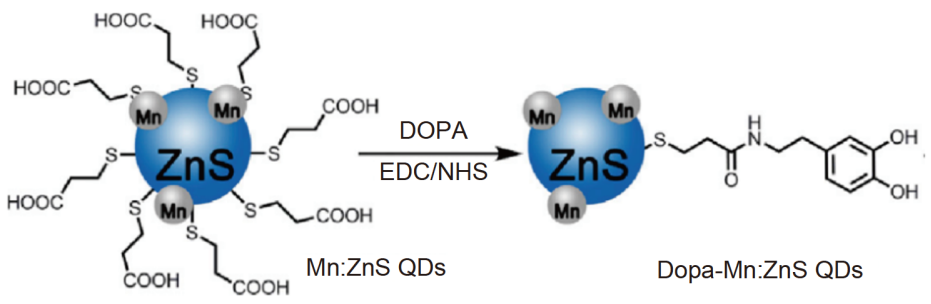

d

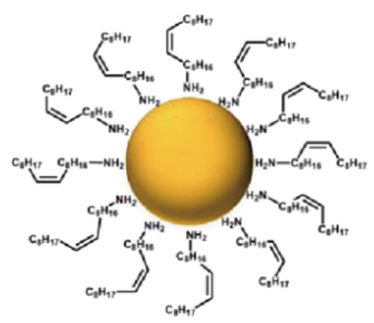

Oleylamine-capped QDs (soluble in nonpolar solvent)
Ligand exchange

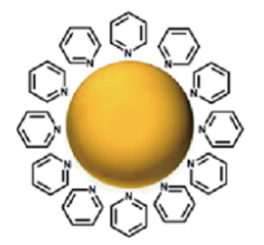

Pyridine-capped QDs (soluble in polar solvent)

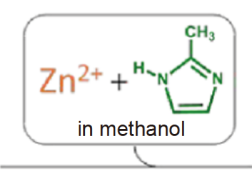

Ligand exchange

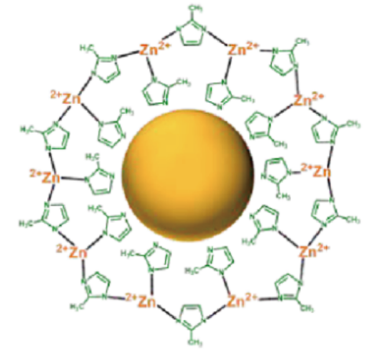

e

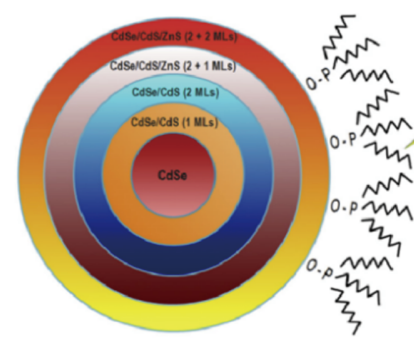

CdSe/CdS/ZnS(2 MLs) capped with TOP (water insoluble)

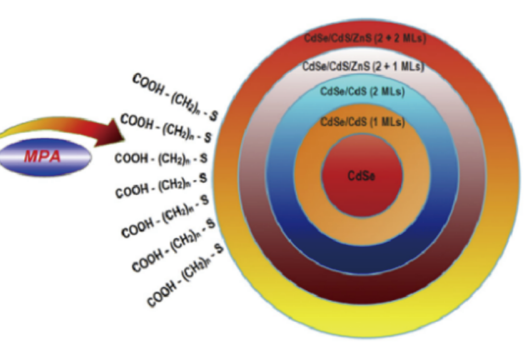

CdSe/CdS/ZnS(2 MLs) capped with MPA (water soluble)

Figure 2 Methods for attaching functional units to the surface of SQDs. (a) Silica-coating. Reprinted with permission from Ref. [101], Copyright 2001, American Chemical Society. (b) Coordination. Reprinted with permission from Ref. [102], Copyright 2016, American Chemical Society. (c) Esterification. Reprinted with permission from Ref. [103], Copyright 2017, Elsevier B.V. (c) Ligand exchange. Reprinted with permission from Ref. [104], Copyright 2019, Royal Society of Chemistry. (e) Phase transfer. Reprinted with permission from Ref. [105], Copyright 2016, Elsevier B.V.

characteristics of the original $\mathrm{CdSe} / \mathrm{ZnS}$ cores, but their silica bead helped to introduce biological functional groups. Even in buffers that simulate physiological en- vironments, silica-coated CdSe/ZnS QDs also displayed high stability. Coordination is also a simple method to connect functional groups. As shown in Fig. 2b, lantha- 
nides have strong coordination ability, which makes them self-assemble to the surface of SQDs [102]. On this basis, other functional groups, such as amino acids and proteins, can be further modified on the surface of SQDs via coordination. In addition, esterification (Fig. 2c) [103], ligand exchange (Fig. 2d) [104], or phase transfer (Fig. 2e) [105] are also common approaches for the surface functional modification of SQDs.

Sometimes, different shells with a modified group [106] may be coated onto the core to achieve precise experimental purposes. An $N$-acetyl- $L$-cysteine (NAC)-capped $\mathrm{CdTe} / \mathrm{CdS} / \mathrm{ZnS}$ core/shell/shell QDs-based "OFF-ON" fluorescent biosensor was constructed to sensitively and specifically test $L$-ascorbic acid [107]. The detection limit could reach $1.8 \times 10^{-9} \mathrm{~mol} \mathrm{~L}^{-1}$ under optimum conditions. The approach was successfully applied to human urine samples, three synthetic samples, and vitamin $C$ tablets.

Mainly classic biological modification approaches for SQDs were introduced above. These modifications make SQDs more compatible with the needs of biomedical applications. Moreover, lanthanide (Ln) is an ideal synergistic material. Ln ions have a long fluorescence lifetime, which is easy to distinguish from short-lived biological background fluorescence via time-resolved techniques [108]. The significant Stokes shift of Ln [109] can effectively improve the resolution of the detection signal. More importantly, there is an energy transfer between Ln ions and the original materials. Based on the energy transfer, the fluorescence intensity of $\mathrm{Ln}$ ions or original materials will be sharply increased. The combination of Ln ions and SQDs via Förster resonance energy transfer (FRET) is considered an exceptional tool for biological analysis [110]. The absorption of SQDs is strong and spectrally broadband, but their fluorescence lifetime is quite short. There is no broad absorption of Ln ions; however, the fluorescence lifetime of Ln ions can last up to milliseconds. After doping, the Ln-SQDs materials combine the optical advantages of Ln ions and SQDs, which is more conducive to the applications in bioimaging, biosensing, and other biomedical fields. The attraction is that both Ln ions and SQDs can be used as energy acceptors and energy donors. FRET can occur when the excited donor fluorophore and the ground-state acceptor fluorophore are in close proximity (generally 1-20 nm) [111]. FRET can occur not only from Ln ions to SQDs but also from SQDs to Ln ions. $\mathrm{Eu}^{3+}$ was incorporated into a CdS lattice via a simple methodology based on the direct precipitation of CdS nanocrystals with 1-thioglycerol as a capping molecule. A previous study revealed an effective energy transfer process from $\mathrm{CdS}$ to
$\mathrm{Eu}^{3+}$ and indicated that the energy transfer process involved surface localized states that could be mediated by a thermally activated exchange mechanism [112]. A facile sol-gel method was used to prepare $\mathrm{Eu}^{3+}$-doped $\mathrm{ZnS}$ nanocrystals. Even though $\mathrm{Eu}^{3+}$ did not appear in the $\mathrm{ZnS}$ lattice, an energy transfer from $\mathrm{ZnS}$ to $\mathrm{Eu}^{3+}$ occurred [113]. It did not matter whether the Ln ions entered the QDs lattice or not, and the energy transfer phenomenon could occur when the Ln ions and QDs were spatially close. Ln ions working as the energy donors and CdSe/ ZnS QDs serving as energy acceptors have also been reported [114]. The energy transfer phenomenon can be observed by QD emission increases of 1000-fold with simultaneous Ln emission quenching. As introduced, the cooperation between $\mathrm{Ln}$ ions and SQDs is very flexible. Certain complementarities of Ln ions and SQDs in optical properties can be combined by FRET. The direction of energy transfer between the Ln ions and the QDs can be selected according to the application needs when designing functional materials.

In summary, water solubility and low biotoxicity are the primary factors considered in biomedical applications. Presently, the water solubility of SQDs can be solved by simple surface modification. The design of the core/shell structure of SQDs may reduce biotoxicity, but unfortunately, the reduction ratio is limited. Once the concentration of QDs is increased, the risk of metal leakage is inevitable. To ensure low biological toxicity, some surface modification is necessary to generate SQDs with certain selectivity and specificity. The modified SQDs showed excellent performances for in vitro experiments. New problems, however, must be addressed when SQDs are used in biological systems. The introduction of modifiers may increase biological toxicity and the particle sizes of the modified SQDs are usually very large, leading to further problems. SQDs with high selectivity and specificity may have relatively high biotoxicity. With larger QD particle sizes, the survival rate of cells decreases. These limit the application of SQDs in the field of biosensing and bioimaging to a certain extent. Without considering the toxicity of the modifier and the particle size of the SQDs, there is good tissue-penetrating ability of near-infrared SQDs. Ln-modified SQDs can also reduce the interference of bioluminescence via a timeresolved fluorescence technique. Additionally, the rapid and large-scale synthesis of SQDs can gradually push SQD technology from scientific research to practical applications. In general, SQDs can meet the needs of biomedical applications within a specific range.

Some studies may need to be considered. The con- 
centration of dopants in the as-prepared SQDs should be precisely controlled, and the particle sizes of SQDs need to be minimized to ensure low toxicity. The fluorescence intermittency of SQDs must be overcome if the SQDs are used for single-molecule tracking. The investigation of the biological metabolism of SQDs cannot be ignored, especially in different cells, tissues, and even organs.

\section{BIOMEDICAL APPLICATIONS}

\section{Biological imaging}

Table 2 [115-131] summarizes the SQD materials for bioimaging. One of the unique properties of SQDs is tunable emission wavelengths [132]. Therefore, some reports have summarized the optimal emission peaks for
SQDs, while others have reported emission ranges of SQDs. The particle sizes referred to in Table 2 are the results derived from transmission electron microscopy images, and they are not hydrodynamic diameters. The particle sizes and hydrodynamic diameters are quite different. For example, in S12, the particle size and hydrodynamic diameter are about 5.6 and $10 \mathrm{~nm}$ in ethanol, respectively. Also, even the same QDs have different hydrodynamic diameters in various solvents. Still, for S12, the hydrodynamic diameters of the QDs in ethanol and water are 10 and $49.2 \mathrm{~nm}$, respectively. Strictly speaking, the QYs in Table 2 are not comparable because the test methods, instruments, and reference materials are different from each other. However, they are still listed to provide a general understanding of QDs.

Table 2 Use of SQDs for biological imaging

\begin{tabular}{|c|c|c|c|c|c|c|c|}
\hline No. & QDs & $\begin{array}{l}\text { Emission wavelength } \\
(\mathrm{nm})\end{array}$ & Size $(\mathrm{nm})$ & Object & Remarks & QY & Refs. \\
\hline $\mathrm{S} 1$ & $\mathrm{CdTe}$ & $510-670$ & $\begin{array}{l}1.4 \pm 0.30 \\
3.3 \pm 0.30\end{array}$ & $\begin{array}{c}\text { HepG2 }^{\mathrm{a}} \\
\text { HO-8910PM }^{\mathrm{b}}\end{array}$ & $\begin{array}{l}\text { Glutathione-capped } \\
\text { Folic acid-conjugated }\end{array}$ & $42.0 \%$ & {$[115]$} \\
\hline $\mathrm{S} 2$ & $\mathrm{CdTe}$ & $530-630$ & 2.7 & SGC-7901 ${ }^{\mathrm{C}}$ & Ribonuclease-A-conjugated & $75.6 \%$ & {$[116]$} \\
\hline S3 & $\mathrm{Cu}^{+}$-doped CdS & 586 & $3.47 \pm 0.44$ & $\mathrm{~KB}^{\mathrm{d}}$ & - & $21.9 \%$ & {$[117]$} \\
\hline S4 & $\mathrm{CdTe} / \mathrm{CdSe}$ & $700-820$ & $5-8$ & $\begin{array}{l}\text { MCF- } 7^{\mathrm{e}} \\
\text { Mouse }\end{array}$ & Multivalent polymer ligands & $66.0 \%$ & {$[118]$} \\
\hline S5 & $\mathrm{CdSe} / \mathrm{CdS}$ & 610 & 6 & $\begin{array}{l}\text { Bel-7404 } \\
\text { Tissue }\end{array}$ & - & $30.0 \%$ & {$[119]$} \\
\hline S6 & $\mathrm{CdS} / \mathrm{ZnS}$ & 500 & $41.2 \pm 5.5$ & Hela $^{\mathrm{g}} / \mathrm{HepG} 2 / \mathrm{A} 549^{\mathrm{h}}$ & Polyethyleneimine-Coated & $10.3 \%$ & {$[120]$} \\
\hline S7 & $\mathrm{CdSe} / \mathrm{ZnS}$ & $538 / 657$ & 4.8 & MGC $803^{\mathrm{i}}$ & $\begin{array}{c}\text { Tumor targeted } \\
\text { Dual antibody-conjugated }\end{array}$ & - & {$[121]$} \\
\hline S8 & $\mathrm{CdTe} / \mathrm{ZnTe}$ & $520-700$ & 3 & $\begin{array}{l}\text { RAW264. } 7^{\mathrm{j}} \\
\text { Panc- }^{\mathrm{k}}\end{array}$ & $\begin{array}{l}\text { Anti-claudin } 4 \text { target } \\
\text { Histological studies }\end{array}$ & $52.0 \%$ & {$[122]$} \\
\hline S9 & $\mathrm{ZnSe} / \mathrm{ZnS}$ & 382 & 3 & $\begin{array}{l}\text { RAW264.7 } \\
\text { SCG7901 }^{1}\end{array}$ & - & $70.6 \%$ & {$[123]$} \\
\hline S10 & Mn-doped ZnS & 600 & $5.3 \pm 1.0$ & MCF-7 & Folic acid-chitosan stabilized & - & {$[124]$} \\
\hline S11 & $\mathrm{ZnS}: \mathrm{Mn} / \mathrm{ZnS}$ & 595 & $4.4 \pm 0.7$ & $\mathrm{~T} 47 \mathrm{D}^{\mathrm{m}}$ & Folic acid-conjugated & $22.1 \%$ & {$[125]$} \\
\hline S12 & $\mathrm{AgInSe}_{2} / \mathrm{ZnS}$ & $700-820$ & $5.0-6.0$ & $\begin{array}{l}\text { MCF-7 } \\
\text { Mouse }\end{array}$ & - & $40.0 \%$ & {$[126]$} \\
\hline S13 & $\mathrm{ZnCuInS/ZnS}$ & $585-715$ & $5.6 \pm 0.4$ & $\begin{array}{l}\text { NIH-3T3 }{ }^{\text {n }} \\
\text { Mouse }\end{array}$ & Hydrophilic ligand and PEG & $26.0 \%$ & {$[127]$} \\
\hline S14 & $\begin{array}{l}\text { Gd-doped } \\
\text { CuInS/ZnS }\end{array}$ & 670 & 3.0 & $\begin{array}{l}\mathrm{U} 87 \mathrm{MG}^{\circ} \\
\text { Mouse }\end{array}$ & $\begin{array}{c}310 \mathrm{~ns} \\
\text { Tumor targeted Fluorescence/ } \\
\text { magnetic resonance }\end{array}$ & - & {$[128]$} \\
\hline S15 & $\mathrm{CdTe} / \mathrm{CdSe} / \mathrm{ZnSe}$ & 670 & $4.0 \pm 0.8$ & Tissue & - & $4.80 \%$ & [129] \\
\hline S16 & $\mathrm{CdTeSe} / \mathrm{CdZnS}$ & $700-800$ & 5.8 & Hela P4 & PEG-phospholipid & $25.0 \%-30.0 \%$ & {$[130]$} \\
\hline S17 & Gd-doped $\mathrm{ZnO}$ & 550 & 4 & HeLa & - & $34.0 \%$ & {$[131]$} \\
\hline
\end{tabular}

a) HepG2: human hepatic carcinoma cell line; b) HO-8910PM: human ovarian cancer cell line; c) SGC-7901: human gastric cancer cells; d) KB: human oral epidermoid carcinoma cell; e) MCF-7: human breast adenocarcinoma cell line; f) Bel-7404: human hepatoma cell; g) Hela: human cancer of cervix cell line; h) A549: human lung carcinoma cell line; i) MGC803: gastric cancer cell line; j) RAW264.7: mice macrophages cell line; k) Panc-1: human pancreatic cancer cells; 1) SCG7901: human gastric carcinoma cell line; m) T47D breast cancer cells; n) NIH-3T3: mouse embryonic fibroblast cell line; o) U87MG: malignant glioma cell. 
The SQDs materials shown in Table 2 enable bioimaging in a wide variety of cells, tissues, and organs, and fluorescence emission of the SQDs from the visible to the near-infrared regions can be achieved. Glutathione-capped CdTe QDs (S1) possesses size-dependent emission ranging from 510 to $670 \mathrm{~nm}$, and the fluorescence emission of ribonuclease-A-conjugated QDs can be adjusted from 530 to $630 \mathrm{~nm}$. Thus, different modifications can directly affect the optical properties of QDs. S1, at sizes of $1.40 \pm 0.30$ and $3.30 \pm 0.30 \mathrm{~nm}$, displays 510 and $670 \mathrm{~nm}$ fluorescence emissions, respectively. These two QDs can be further conjugated with folic acid for targeted fluorescence imaging. HepG2 and HO-8910PM have been selected for imaging objects because they are known to express abnormally high levels of folate receptors on their cell surface. S7 not only has targeted imaging capabilities in vitro but can also realize targeted imaging in vivo. BRCAA1 monoclonal antibody and Her2 antibody were chosen to conjugate with the QDs. The BRCAA1 antigen is a specific protein for the intracellular epitope of histone deacetylase complex subunit SAP180, expressed in the cytoplasm of the breast cancer cell line MCF-7 and gastric cancer cell line MGC803 [133], and HER2 is confirmed to be overexpressed in gastric cancer and some other aggressive diseases [134]. As expected, the cytoplasm of MGC803 cells, where the BRCAA1 protein is mainly expressed, is evenly labeled by the red signals of BRCAA1 monoclonal antibody-modified QDs, and the membranes of MGC803 cells are labeled by the green signals of HER2 antibody-modified QDs. Similar [135] and other celltargeted imaging studies are receiving increased attention.

CdS QDs are used in both S3 and S6, which form metal doping and core-shell structure materials. Inevitably, the particle size of S6 is greater than that of S3. However, not all core-shell materials have larger sizes. For example, the particle sizes of S4 and S5 are almost the same as those of S3. The performance differences caused by the metal doping and core-shell modifications are still noticeable. The optimal emission peaks for S3 and S6 are 586 and $500 \mathrm{~nm}$, respectively. Compared with S6, although S3 has no passivation shell, the QY still reaches $21.82 \%$. As a core-shell material, S6 can easily be further functionalized with folic acid. It can be used not only as a sensitive and selective fluorescence probe for folate receptors, but also to realize the targeted imaging of Hela cells. Some metaldoped SQDs can also be biologically modified, like the corresponding core-shell SQDs in S10 and S11. S10 uses Mn-doped ZnS QDs, and S11 uses Mn-doped ZnS as the core and with a $\mathrm{ZnS}$ shell modification on the outside. Although the optimal emission peaks of the two SQDs are approximately the same, and each one could be folatefunctionalized for cell-targeted imaging, there are still differences in some properties. The ZnS shell provides effective passivation and elimination of surface defects on the $\mathrm{ZnS}: \mathrm{Mn}$ core surface, which is demonstrated by the high QY (22\%) of the core/shell SQDs compared with the ZnS:Mn QDs (2.7\%).

Both S4 and S8 are core-shell structure QDs with CdTe as the core. However, different shell materials endow QDs with distinct optical properties. The fluorescence emissions of S4 are tunable between 700 and $820 \mathrm{~nm}$, and the fluorescence emission range of S6 is from 520 to $700 \mathrm{~nm}$. Similarly, when the shell material is the same, and the core material is different, the optical properties of the SQDs are also greatly different. As shown in S6, S7, S9, S12, and S13, their optimal fluorescence emission peaks are very distinct. Thus, the materials for the core and the shell can be chosen according to the actual wavelength requirements of the cell imaging.

Near-infrared light not only can be clearly distinguished from the background fluorescence of the biological sample itself but also has stronger tissue penetration [136], so the preparation and modification of near-infrared imaging SQDs materials have also become the focus of attention. CdTe, CdSe and other SQDs have been studied because of their long fluorescence emission wavelengths, although, the emission of CdSe-based QDs is only from 650 to $700 \mathrm{~nm}$, which is still below the optimal near-infrared range of $700-900 \mathrm{~nm}$ for in vivo imaging. This does not prevent it from combining with other materials to form near-infrared emission SQDs, such as $\mathrm{CdTe} / \mathrm{CdSe}$ core/shell QDs (S4), with emissions ranging from 700 to $820 \mathrm{~nm}$. Some multi-element materials have also been designed as QDs for near-infrared cell imaging, such as $\mathrm{AgInSe}_{2} / \mathrm{ZnS}$ (S12) and CdTeSe/CdZnS (S16) QDs. In addition to designing QDs as the core/shell structures mentioned above, the materials can also be designed as core/shell/shell structures. As shown in S15, the optimal emission peak position of $\mathrm{CdTe} / \mathrm{CdSe} / \mathrm{ZnSe}$ QDs is $670 \mathrm{~nm}$ which is obviously larger than that of the original CdTe core $(530 \mathrm{~nm})$, and the fluorescence emission can be tuned from 550 to $800 \mathrm{~nm}$. If the mercaptoundecanoic acid amount is reduced in the synthesis, the emission peak will be further red-shifted for $57 \mathrm{~nm}$.

Ln-doped SQDs for imaging are relatively special because imaging includes not only fluorescence imaging but also magnetic resonance imaging. Besides, the characteristic feature of Ln-doped QDs is their long lifetime; the lifetime of S14 can be as long as 310 ns. As shown in Fig. 3, S14 can perform fluorescence imaging and mag- 


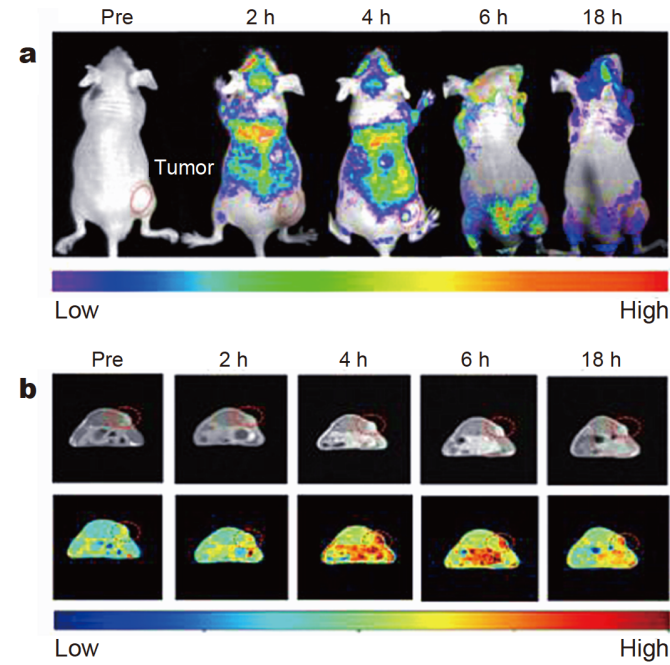

Figure 3 In vivo fluorescence imaging (a) and $\mathrm{T}_{1}$-weighted imaging (b) of U87 tumor-bearing mice after tail-vein injection of S14 at various time intervals (pre, 2, 4, 6 and $18 \mathrm{~h}$ ). Reprinted with permission from Ref. [128], Copyright 2015, American Chemical Society.

netic resonance imaging in vivo. It is worth noting that the fluorescence signals nearly disappeared $18 \mathrm{~h}$ of postinjection, indicating that most of the SQDs could be gradually removed from the body. Compared with conventional contrast agents (Gd-DTPA), SQDs can realize stronger imaging intensity and relatively long circulation time in the body, which provides a longer imaging time window for the technicians. In addition, SQDs can present better permeability and retention effects than GdDTPA, although the Gd doped-ZnO QDs performed the same as S14. However, the nature of the host material itself causes its fluorescence emission range to be significantly different from that of S14. Although the emission peak position of S17 could be adjusted by the doping amount of Gd, the optimal emission peak position can only vary between 525 and $575 \mathrm{~nm}$, far from $670 \mathrm{~nm}$ (S14). The magnetic resonance imaging resolution was also significantly lower than that of S14.

In addition to the animal cell imaging mentioned above, SQDs are also widely used in the field of microbial imaging [137]. Lin et al. [138] made Staphylococcus aureus work as a living substrate to prepare CdSe QDs with high brightness, strong light stability, and uniform brightness. The fluorescent bacterial probe still retained the ability to be recognized and phagocytosed by macrophages. This live bacterial fluorescent probe could be used as a multifunctional tool for biological research on Staphylococcus aureus. Mir et al. [139] prepared AgInS@ZnS QDs with a high fluorescence lifetime
(> $300 \mathrm{~ns}$ ) and high QY (49\%) for stable imaging in Candida albicans. The QDs could also be applied as a carrier to deliver photosensitizers for cancer diagnosis and photodynamic therapy. Hong et al. [140] used the conjugation of 4-formylbenzoate modified CdSe QDs to 6-hydrazinonicotinate acetone hydrazone-modified viruses to achieve fluorescent labeling of the H9N2 virus. This labeling method not only made the labeling efficiency as high as $92 \%-93 \%$, but also maximized the retention of viral infectivity. This labeling strategy can be applied to both enveloped and non-enveloped viruses.

In general, many types of SQDs can be used for imaging, and they can be metal-doped SQDs, core-shell SQDs, metal-doped core-shell SQDs, or other forms of SQDs. The overall fluorescence emission range covers visible to near-infrared light. The types of imaging objects include animal cells, tissues, organs, bacteria, fungi and viruses. Although the biotoxicity of SQDs has been criticized, it is undeniable that the excellent optical properties of SQDs make them exhibit satisfactory imaging capabilities in most cell samples. According to the specific or overexpressed substances in the nucleus and cytoplasm of some tumor cells, SQDs can be functionalized to achieve targeted imaging of cells or tissues. On this basis, according to the size-dependent effect of the SQDs, SQDs with different fluorescence emission wavelengths can be prepared, which can realize dual-light cell imaging of the same type SQDs by various targeted modifications. The SQDs achieve not only fluorescence imaging but also magnetic resonance imaging. Compared with existing commercial contrast agents, although many studies on SQDs need to be performed before clinical application, they show some absolute advantages in animal experiments. As summarized, SQDs have performed well in the imaging field. But many problems still need to be solved. The current research on SQDs used for imaging has mainly focused on material preparation, characterization, cytotoxicity testing, and general in vitro/in vivo imaging/ targeted imaging. Many aspects of QD imaging still need to be explored.

Next, the development of SQDs in the field of imaging should closely combine with research on the immunity and metabolism of cells, tissues, and organs. Based on this work, targeted imaging can be explored to guide actual clinical medicine. For example, targeted imaging techniques can be used to outline tumor boundaries for tumor resection in non-precise areas. After this technology is mature, tumor resection can be performed at precise sites. Some tumor surgery in specific, defined locations, including brain tumor resection, can damage normal brain 
cells if a small error occurs in the resection, which may cause irreversible lifelong bodily injury. However, it is difficult to accurately distinguish tumor cells from normal cells with the naked eye, meaning that surgeries are extremely difficult. Once targeted imaging technology is mature enough to outline the tumor boundaries for such surgeries, it will significantly increase the success rate of the operation. Conservative treatments such as chemotherapy can be gradually replaced by active surgical procedures on a large scale. Existing in vivo imaging techniques can only display the planar conformation of the imaged area, and the actual volume of the imaged area cannot be determined. Therefore, it is impossible to provide accurate pre-judgment for the above-mentioned surgeries. However, the imaging technology of QDs has not matured. On the contrary, related research on imaging is just beginning.

\section{Drug delivery}

Although drug-delivery-related research on QDs has not entered the clinical research stage, they have brought new hope for the cure of major human diseases, especially cancer. Table 3 [26,141-152] lists the current drugdelivery materials based on SQDs. The various compositions and modifications make them exhibit different characteristics in drug-delivery studies.

The blue-light emitting ZnO QDs mentioned in s1 have been combined with chitosan and folic acid for tumortargeted doxorubicin (DOX) delivery, and the drugloading efficiency reached $75 \%$. With the hydrophilicity and cationic charge characteristics, chitosan increases the stability of the QDs. Folic acid is used to weaken the electrostatic interaction between DOX and QDs in the ZnO-QDs-chitosan-folate carriers and the binding affinity between DOX and the carriers is the primary factor influencing the DOX-releasing response. The carrier shows the characteristic of $\mathrm{pH}$ insensitivity. The s2 also reports a $\mathrm{ZnO}$ QD-based DOX delivery platform. Dicarboxyl-terminated polyethylene glycol (PEG) is introduced to render the carrier stable in physiological fluids, and the hyaluronic acid is conjugated to the carrier as a targeting ligand. This DOX delivery platform is $\mathrm{pH}-$ sensitive, and the release of DOX is triggered by the dissolution of the $\mathrm{ZnO}$ QDs and dissociation of DOXmetal complex under acidic conditions. Furthermore, the acidic environment provided by tumors can completely biodegrade the $\mathrm{ZnO}$ QD carriers. After dissolution, the carriers alone display antitumor activity by preferentially killing cancer cells. Both s1 and s2 are ZnO QD-based DOX-delivery carriers. However, their DOX-releasing

Table 3 Use of SQDs for drug delivery

\begin{tabular}{|c|c|c|c|c|c|c|}
\hline No. & QDs & Modifier & Remarks & Drug & Object & Refs. \\
\hline s1 & $\mathrm{ZnO}$ & $\begin{array}{l}\text { Chitosan } \\
\text { Folic acid }\end{array}$ & $\mathrm{pH}$ non-sensitive & DOX & - & [26] \\
\hline s2 & $\mathrm{ZnO}$ & $\begin{array}{c}\text { Hyaluronic acid } \\
\text { PEG }\end{array}$ & $\mathrm{pH}$ responsive & DOX & A549 & {$[141]$} \\
\hline s3 & $\mathrm{CdTe}$ & Silica mesoporous & Selective release & DOX & Hela & {$[142]$} \\
\hline s4 & $\mathrm{CdTe}$ & Polyethylene glycol & Regulate the protein expressions & DOX & PRMI $8226^{\mathrm{a}}$ & {$[143]$} \\
\hline s5 & $\mathrm{CdSe} / \mathrm{ZnS}$ & - & Antibacteria & Qe & BGC- $-823^{\mathrm{b}}$ & {$[144]$} \\
\hline s6 & $\mathrm{CdSe} / \mathrm{ZnS}$ & GEM nanovectors & Dual enzymatic reactions & GEM & $\mathrm{BxPC}-3^{\mathrm{c}}$ & {$[145]$} \\
\hline s7 & ZnO@polymer & - & pH-Triggered & DOX & $\mathrm{U} 251^{\mathrm{d}}$ & {$[146]$} \\
\hline s8 & ZnO,Au@polymer & Copolymer & Cooperation effect & $\mathrm{CPT}$ & Hela & {$[147]$} \\
\hline s9 & $\mathrm{Mn}: \mathrm{ZnS}$ & $\begin{array}{l}\text { Folic acid } \\
\text { Chitosan }\end{array}$ & Attenuate tumor resistances & 5-FU & $4 \mathrm{~T} 1$ & {$[148]$} \\
\hline s10 & ZnSe:Mn/ZnS & $\begin{array}{c}\text { Folate } \\
\text { Hybrid silica } \\
\text { F127 micelles }\end{array}$ & Linearly release behavior & PTX & - & [149] \\
\hline s11 & $\mathrm{CdSe} / \mathrm{ZnS}$ & $\begin{array}{l}\beta-C D \\
L-\arg \end{array}$ & Produce ROS & DOX & HepG2 & {$[150]$} \\
\hline s12 & $\mathrm{CuInS}_{2} / \mathrm{ZnS}$ & $\mathrm{SiO}_{2}$ nanohybrids & Efficient assistance of drug delivery & $\operatorname{Pt}(\mathrm{IV})$ & MCF-7 & {$[151]$} \\
\hline s13 & $\mathrm{Fe}_{3} \mathrm{O}_{4} @ \mathrm{ZnO}: \mathrm{Er}^{3+}, \mathrm{Yb}^{3+} @(\beta-\mathrm{CD})$ & - & Microwave-triggered drug release & Etoposide (VP-16) & MCF-7 & {$[152]$} \\
\hline
\end{tabular}

a) PRMI 8226: multiple myeloma line; b) BGC-823: gastric carcinoma; c) BxPC-3: human pancreas adenocarcinoma cell; d) U251: human glioblastoma cells. 
triggers and induction of tumor cell apoptosis are quite different. In addition to the drug release influences mentioned above, the drug release behavior is affected by many factors, such as surface properties, the degradation rate, particle size, the interaction force of drug binding to the surface, and the rates of dehydration and hydration of the polymers [153].

The CdTe QDs introduced by s3 are coated by modified mesoporous silica nanoparticles, which lead to pore size improvements with better encapsulation and controlled release. Also for the consequent release inside the cell, DOX was observed to only be released while the carriers were inside the cells. The $\mathrm{pH}$-triggered CdTe QD delivery carrier (PEG-CdTe-DOX) mentioned in $s 4$ was modified by PEG, which facilitated intracellular drug accumulation. The PEG-CdTe-DOX was found to enhance the cytotoxic effects to tumor cells via inducing apoptosis via the caspase-mediated apoptotic pathway. That is, the anti-tumor activity of DOX could be improved by PEG-CdTe-DOX via regulation of the protein expression of apoptosis-associated genes.

The s5 and s6 represent CdSe/ZnS QD-based delivery carriers. The Qe/CdSe/ZnS nanoparticles (s5) are more cytotoxic than quercetin (Qe) and Qe/CdSe/ZnS, which is attributed to the sustained-release of Qe from the Qe/ $\mathrm{CdSe} / \mathrm{ZnS}$ nanoparticles. This sustained-release may enhance the Qe uptake by the tumor cells for Qe loaded into the amine-enriched CdSe QDs. Besides, the Qe/CdSe/ZnS nanoparticles displayed effective antibacterial activities via disrupting the bacterial cell wall and membrane. The s6 shows dual-enzyme-sensitive gemcitabine (GEM) nanovectors which are synthesized via the conjugation of matrix metalloproteinase-9 (MMP-9)-detachable PEG, cathepsin B-cleavable GEM, and targeting the ligand CycloRGD ligand to the CdSe/ZnS QDs. GEM nanovectors will accumulate in tumor tissue via enhanced permeability and retention effects. Then, the overexpressed MMP-9 in tumor tissue removes the PEG corona in the tumor microenvironment, which leads to the exposure of RGD. RGD will guide the rest of GEM nanovectors to locate towards the cancer cells. After internalizing into pancreatic cancer cells, the release of GEM can be further promoted by the elevated lysosomal cathepsin B. The dual enzymatic reactions help GEM nanovectors achieve prolonged circulation time.

By comparing s1 with s6, it can be seen that even the same carrier materials will exhibit various forms of functions after different functional modifications. As introduced, the drug cytotoxicity, drug release, drug residence time, and other characteristics can be adjusted according to the actual situation. In addition, functional modifications will also promote drug absorption. Qe (s5) plays an important role in inflammation, antibacterial and anticancer activities, and aging. Unfortunately, the water-solubility of Qe is extremely low, which poses a challenge to drug absorption. After modification of the QDs, the as-prepared nanoparticles possessing high water-solubility can be used in bacteria and tumor cells.

After the above comparison between the same basic carriers, the varied service modes for in vitro or in vivo SQD drug-loading systems will be introduced. The 57 is a pH-responsive ZnO@polymer-DOX drug delivery system. The system is very stable in aqueous solutions at $\mathrm{pH}$ 7.0 and rapidly decomposes at $\mathrm{pH}$ 6.0, which ensures the safety and minimizes healthy concerns. The drug delivery mechanism mainly involves the cellular internalization of ZnO@polymer-DOX, the biodegradation in endosomes/ lysosomes, and the subsequent penetration of DOX into the nucleus. 5-Fluorouracil (5-FU), an anti-cancer drug used to induce thymidine synthase overexpression and cancer cell resistance was chosen to load into the chitosan and folic acid-modified Mn:ZnS QDs in s9, and 4T1 cells were selected to explore the drug delivery mechanism. The architecture of the reticuloendothelial system organs can be significantly affected by $4 \mathrm{~T} 1$ cells that cause lymphocyte depletion and adversely affect the normal liver and kidney metabolic functions. 5-FU delivery systems with targeting specificity can protect the entire reticuloendothelial system by suppressing the proliferative tendency of $4 \mathrm{~T} 1$ cells, including the disruption of the cell growth rate. Besides, the delivery systems have been found to attenuate possible tumor resistances to 5-FU.

The s11 shows the DOX delivery carriers of CdSe/ZnS QDs modified by $\beta$-cyclodextrin $(\beta-C D)$ and $L$-arginine (L-arg). With the presence of $\beta-\mathrm{CD}$, DOX can efficiently go through the cell membranes, and the specific binding of L-arg makes the HepG2 cells more sensitive to the DOX delivery carriers. It is thought that the DOX delivery carriers efficiently induce apoptosis, which may relate to the production of reactive oxygen species (ROS). This mechanism was confirmed by ROS analysis. 2',7'Dichlorodihydrofluorescein diacetate $\left(\mathrm{H}_{2} \mathrm{DCF}-\mathrm{DA}\right)$ is sensitive to the oxidation formed from Fenton reactions of $\mathrm{H}_{2} \mathrm{O}_{2}$ [154]. The QDs, DOX, and DOX-loaded QDs were respectively incubated with DCF in HepG2 cells. The green fluorescence of DCF was observed only in the DOX-loaded QD sample, indicating that the intracellular ROS levels in cells can be significantly increased by treatment with DOX-loaded QDs.

The drug delivery system presented in s12 was prepared 
by silica nanohybrids integrated with $\mathrm{CuInS}_{2} / \mathrm{ZnS}$ QDs and magnetite nanocrystals. The PEG and amine groups were grated with the outside $\mathrm{SiO}_{2}$ shell, which provides better biocompatibility and allows subsequent bioconjugation. The Pt (IV) was used as the model drug and conjugated with $\mathrm{SiO}_{2}$ nanohybrids via the $\mathrm{NH}_{2}$ functional groups, which was then reduced in the intracellular milieu to generate cytotoxic Pt (II) by reductive elimination of the axial ligands [155].

Fig. 4 (s10) shows that the hydrophobic ZnSe:Mn/ZnS core-shell QDs and the anticancer drug paclitaxel (PTX) were co-loaded into folate-conjugated hybrid silica nanocapsules via F127 micelles (abbreviated as QPNCPs), and the optical properties of the composite nanocapsules were dependent upon the F127:QDs mass ratio-dependent behavior. The linear release behavior of PTX from the QPNCPs was observed within $12 \mathrm{~h}$, which provided a certain amount of PTX concentration in the blood circulation system. Besides, the QPNCPs greatly enhanced the solubility of PTX by up to 630 times. The sustained release performance and enhanced solubility were attributed to the hydrophobic PPO block of the F127 molecules and the rigid structure introduced by the $\mathrm{SiO}_{2}$ shell. Another nanocarrier (s8) could also achieve the controlled release of hydrophobic anticancer drugs. The core-shell targeted delivery nanocarrier of camptothecin (CPT) is composed of $\mathrm{ZnO}$ QDs-conjugated gold nano- particles (Au NPs) as the core and an amphiphilic hyperbranched block copolymer as a shell that include a poly-L-lactide (PLA) inner arm and an outer arm of FAconjugated sulfated polysaccharide from Gynostemma pentaphyllum Makino (GPPS-FA). The controlled release behavior follows a diffusion-controlled mechanism, and the GPPS on the surface of the carrier makes the delivery nanocarrier more effective in killing tumors via the cooperation between the carriers and CPT.

The drug delivery carriers summarized above all use in vivo factors as a trigger for drug release. The s13 introduced a kind of nanocarrier, which is a noninvasive, externally controlled drug-delivery system. The nanocarrier (abbreviated as $\mathrm{Fe}_{3} \mathrm{O}_{4} @ \mathrm{ZnO}: \mathrm{Er}^{3+}, \mathrm{Yb}^{3+} @ \beta-\mathrm{CD}$ ) was synthesized with a $\mathrm{Fe}_{3} \mathrm{O}_{4}$ core and a $\mathrm{ZnO}: \mathrm{Er}^{3+}, \mathrm{Yb}^{3+}$ shell, and the chemically inert $\beta-\mathrm{CD}$ cavity stored etoposide (VP-16) molecules using hydrophobic interactions (Fig. 5). The $\mathrm{ZnO}: \mathrm{Er}^{3+}, \mathrm{Yb}^{3+}$ shell is a good microwave absorber and its excellent microwave thermal response property is used in the microwave-triggered VP-16 release. The release profile can be adjusted by the duration and number of cycles of microwave application.

In summary, we reviewed some representative SQDbased drug delivery systems. Although SQDs as basic carrier materials do not play a decisive role in the efficacy of the entire drug-delivery system, some QDs can synergize with drugs to increase the drug toxicity. Func-

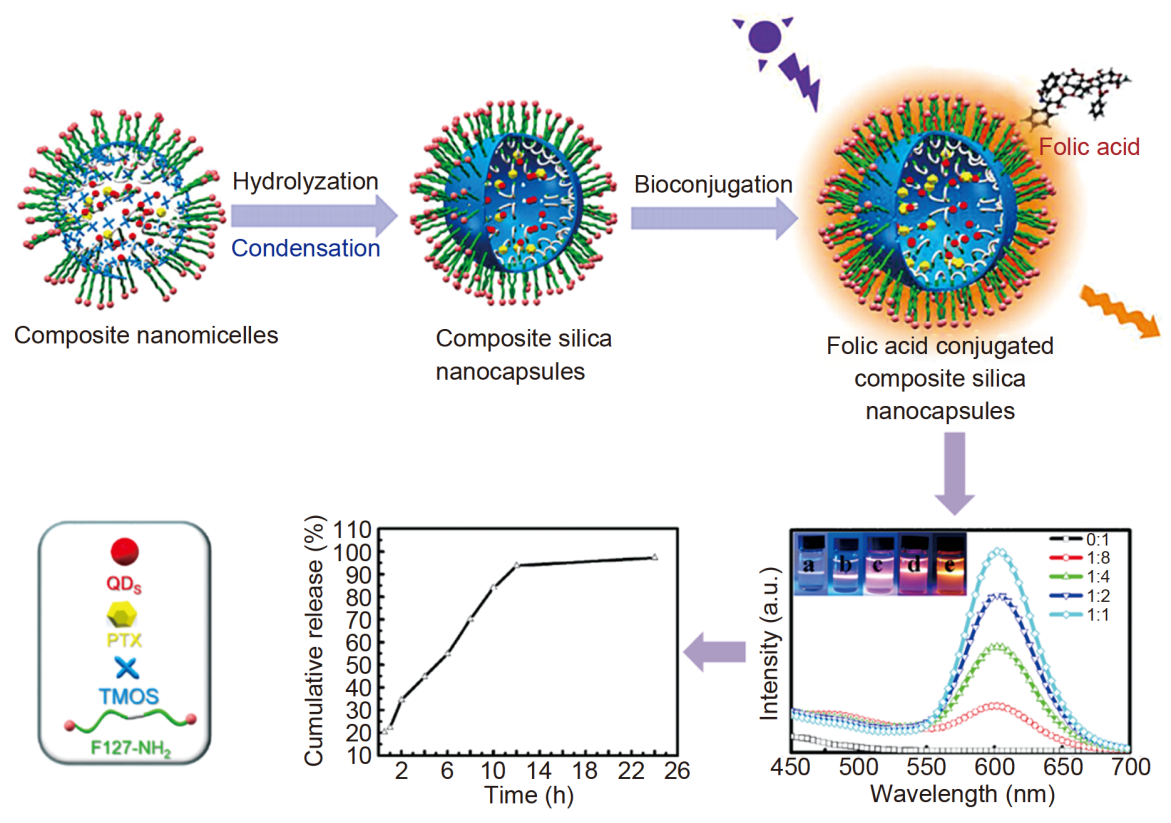

Figure 4 Schematic assembly of $\mathrm{ZnSe}: \mathrm{Mn} / \mathrm{ZnS}-\mathrm{PTX} / \mathrm{SiO}_{2}$ nanocapsules templated by F127 micelles; the fluorescence spectra and images (the inset photographs, excited at $375 \mathrm{~nm}$ ) of QNCPs; the cumulative release of PTX in QPNCPs within $24 \mathrm{~h}$. Reprinted with permission from Ref. [149], Copyright 2016, Elsevier Inc. 


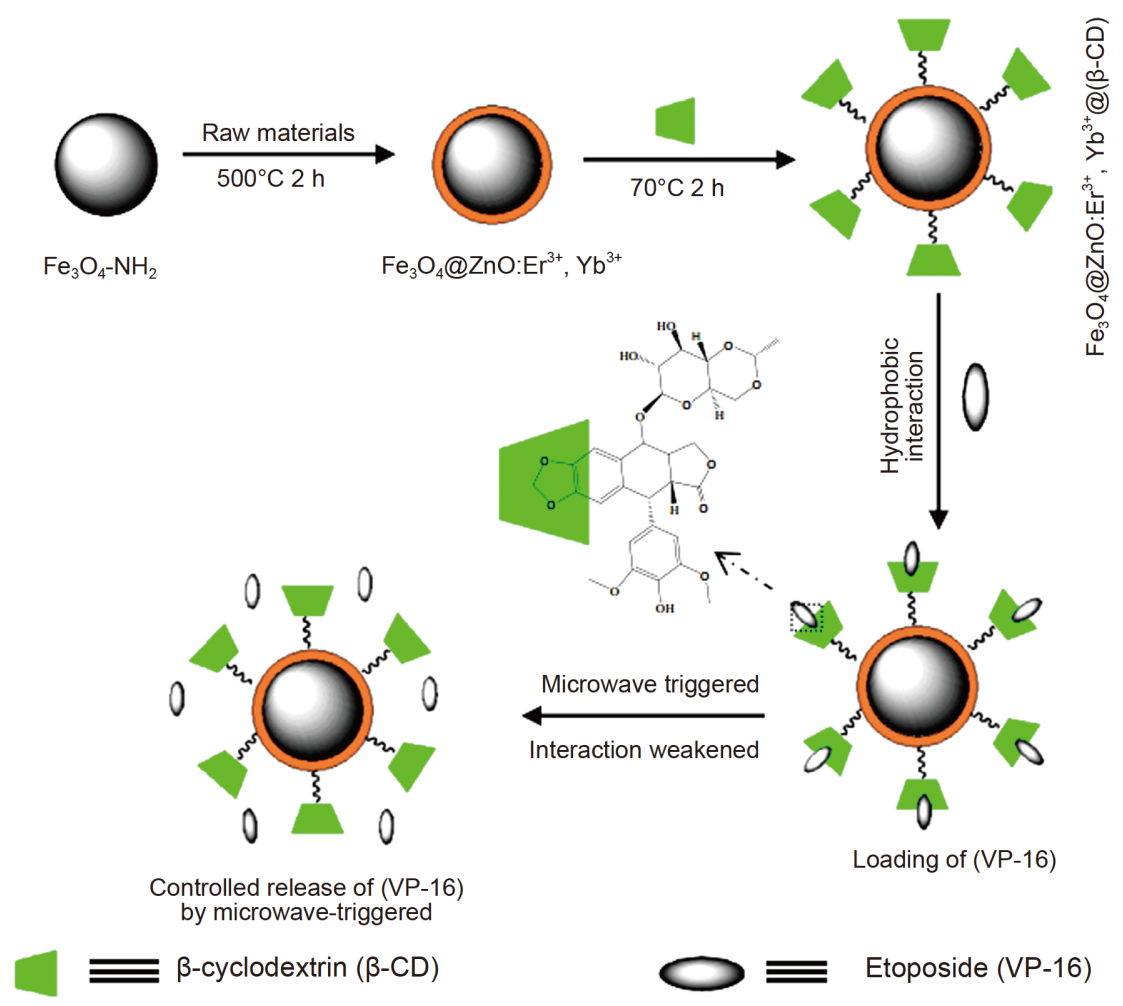

Figure 5 Schematic illustration of $\mathrm{Fe}_{3} \mathrm{O}_{4} @ \mathrm{ZnO}: \mathrm{Er}^{3+}, \mathrm{Yb}^{3+} @ \beta$-CD nano-composites and the controlled release of VP-16 by microwaves. Reprinted with permission from Ref. [152], Copyright 2014, Elsevier B.V.

tional modifications of the carriers can be used to develop the drug delivery systems into different service models. For the loaded drug, a drug with low solubility can gain considerable solubility by incorporating it into a drugloading system. Some drugs can achieve sustained release by being coated in a hydrophobic cavity of the carrier. In other modifications, such as with PEG, the material can afford the carriers better biocompatibility. The porous structure of silica materials allows for the regulation of the loading amount of the drug. An identification group, such as folic acid, can provide the corresponding targeting property to the carriers. Also, the modification not only determines the trigger of the drug release for the carriers, but also affects the way the drug induces apoptosis in tumor cells.

We reviewed SQD-based materials in the field of drugloaded delivery research and summarized their respective strengths and highlights based on typical or classic instances. However, there are still many common problems in SQD-based delivery systems that need to be improved and solved. For example, among many anticancer drugs, DOX with a broad antitumor spectrum can be used in the chemotherapeutic treatment of many human malig- nancies, such as breast cancer, bladder cancer, multiple myeloma, lymphoma, and small cell lung cancer [156]. Therefore, DOX is used as a loaded drug in many cases, but DOX is a type of drug that works after intercalating into DNA [157]. DOX interacts with DNA by inserting and inhibiting the biosynthesis of macromolecules [158]. Topoisomerase II used to untie the DNA supercoil structure is inhibited by this effect. After topoisomerase II unfolds the DNA preparing for replicating, DOX will stabilize topoisomerase II to prevent the DNA doublehelix from recombining, thereby stopping the replication process. Therefore, if DOX cannot assuredly enter the nucleus smoothly, then DOX can only act on the cells in the disappeared period of the nuclear membrane and nucleolus. It is not easy to carry drugs into the nucleus. There are thousands of nuclear protein complexes on the nuclear membrane. These nuclear pores and specific nuclear importin combine to form a cryptographic substance exchange system [158]. Synthetic nanomaterials have difficulties entering the nucleus due to the lack of specific binding functions. Nuclear targeting studies of some other materials can provide some reference for QD drug delivery. The nuclear localization signal (NLS) ex- 
tracted from SV40 large T is used to deliver Au nanoparticle with $25 \mathrm{~nm}$ to cell nuclei. Therefore, it is conceivable to modify the delivery system with NLS and some tumor identifiers simultaneously. The tumor identifier would be used to locate the drug delivery system to the tumor cells. After the drug delivery system enters the interior of the cell, the NLS would bring it to the cell nucleus. This dual-targeting location approach is applicable to drugs inducing cell apoptosis, such as DOX, via entering into the nucleus to act on DNA. Based on the above, the dosage of the drug would be greatly reduced, which would help to prevent the development of drug resistance in the tumor cells. DOX can also be combined with substances produced by the cells themselves, such as colyone, which is a type of molecule signaling the termination of cell proliferation. It not only increases the specificity of the drug-loading system but also reduces the rejection of cells to foreign substances.

As far as current research is concerned, $\mathrm{pH}$ is the main trigger for drug release. Other triggers include enzymes, microwaves, light sources, and magnetic fields. Also, signal molecules (generated during excess cells proliferation), local high temperature or low temperature, and ultrasound can all be attempted to be used as the triggers for drug release. But no matter which trigger method is used, it will lead the drug delivery system to continue to release the drug once it starts. However, this continuous drug release method may not be applicable for some clinical uses where the induction of cell apoptosis is not needed. For example, in some osteosynthesis procedures, it is necessary to implant the drugs promoting bone growth into the fracture. However, each patient's recovery ability is different. Local bone hyperplasia will happen if the administration is excessive. In this instance, the dose of drug administered must be controlled according to the actual situation, which raises new challenges for drug delivery research. One challenge is to build the real on-off drug delivery system. That is, the drug delivery system can control the initiation and termination of the drug release, even the amount of dose per unit time can be adjusted according to the trigger intensity. Another challenge is that these cases have a long recovery period and require long-term administration. As far as current long-term drug studies are concerned, it is still difficult to extend the administration time to several months. In the introduction, we introduced the advantages of combination of lanthanide materials and QDs in detail, but the functional materials relating to these are still relatively few. The combination of lanthanide metalorganic framework (MOF) materials and QDs may pro- vide a real possibility for true long-term administration. Because the coordination number of the lanthanide ions is more than that of conventional ions, it is conducive to combination with more drug molecules. Besides, MOF materials can provide loadable spaces for the drug.

In the above fluorescence imaging studies, some assumptions for the detection of tumor spread are proposed, which can be combined with drug delivery research. This will not be discussed in detail here. Fluorescence imaging technology can also provide early warning for drug-delivery systems, and it is expected to present different fluorescence chromaticity at various stages of tumor cell growth. If this technique is achieved, different drugs can be simultaneously loaded into the delivery system, which can release specific drugs at homologous wavelengths of different fluorescent chromaticities.

\section{CONCLUSIONS AND OUTLOOK}

In this review, we introduced the SQDs prepared by different modifications for different biomedical applications. In each part, we have summarized and analyzed the advantages and disadvantages of the existing research, and on this basis, some outlooks on the prospects in the corresponding fields are raised. However, there are far more studies of SQDs than these.

For short-term goals, SQDs can be combined with other cutting-edge materials to make full use of their properties. At present, the combination of semiconductor materials with MXene, black phosphorus, TMDCs, and other materials has shown strength in the fields of optics [159], catalysis [160], and sensing [161]. SQDs can look for opportunities to optimize the materials used in these studies. For example, BPQDs have good biocompatibility and capabilities for photothermal and photodynamic therapy. However, the stability of BPQDs is poor, and they are easily oxidized. SQDs have good stability and optical performance. Therefore, nanoparticle composites can be obtained by doping water-soluble SQDs with BPQDs. The new material is expected to combine the advantages of the two materials. By the improvement of these materials, the application of SQDs in the field of biomedicine can be further enriched. SQDs will not only be used for imaging, sensing, and drug delivery. SQDbased materials can be doped into nanofibers due to their advantages of size and excellent biocompatibility, and new composite materials can be made into scaffolds by $3 \mathrm{D}$ printing. Such scaffolds will have better cell affinity and compatibility than traditional materials and can be used as support materials for the treatment of bone and 
cardiovascular diseases.

In the future, SQDs researches should focus on the two keywords of precision and intelligence. As shown in Fig. 6, the growth and luminescence mechanism of materials should be clarified first in fundamental research on SQDs. Clear mechanisms will provide authoritative theoretical reference for the preparation of materials, making it possible to control the synthesis and modification of the materials. Then, the physical and chemical properties of the nanomaterials can also be correspondingly adjusted. Based on these, the door of SQD biotechnology will indeed be opened. In biological application research on SQDs, primary research on the stability, compatibility, and toxicity of SQDs in biosystems still need to be strengthened. In particular, studies on toxicity should not stop at the level of testing cell viability. Studies on the toxicity and metabolism of cells, tissues, and organs after SQDs enter the organism should be part of systematic research.

In functional studies, sensing, imaging, diagnostic, and therapeutic research should be tightly integrated with intelligent electronic devices and communication technologies. For example, in the diagnosis and treatment of cancer, attempts can be made to load functionalized SQDs into specific nanorobots. Nanorobots can enter the body via injection or other routes and reach the lesion through the blood circulating. When the nanorobots are specifically fixed in the lesion, the course of the disease can be monitored at any time. After pairing with an in vitro electronic device, the nanorobot will emit a signal to make the external electronic device sound an alarm if the lesion is abnormal. With the help of portable electronic devices, patients can discretionary decide to make the nanorobots release functional SQDs. The patients can also terminate the process after receiving feedback to prevent damage to normal cells. After servicing its purpose, the robot will be degraded and excreted from the body as they receive instructions. Unused nanorobots can continue to monitor in real-time at the lesion to prevent the recurrence of the disease. In this way, the biological application of SQDs can truly move toward precision and intelligence.

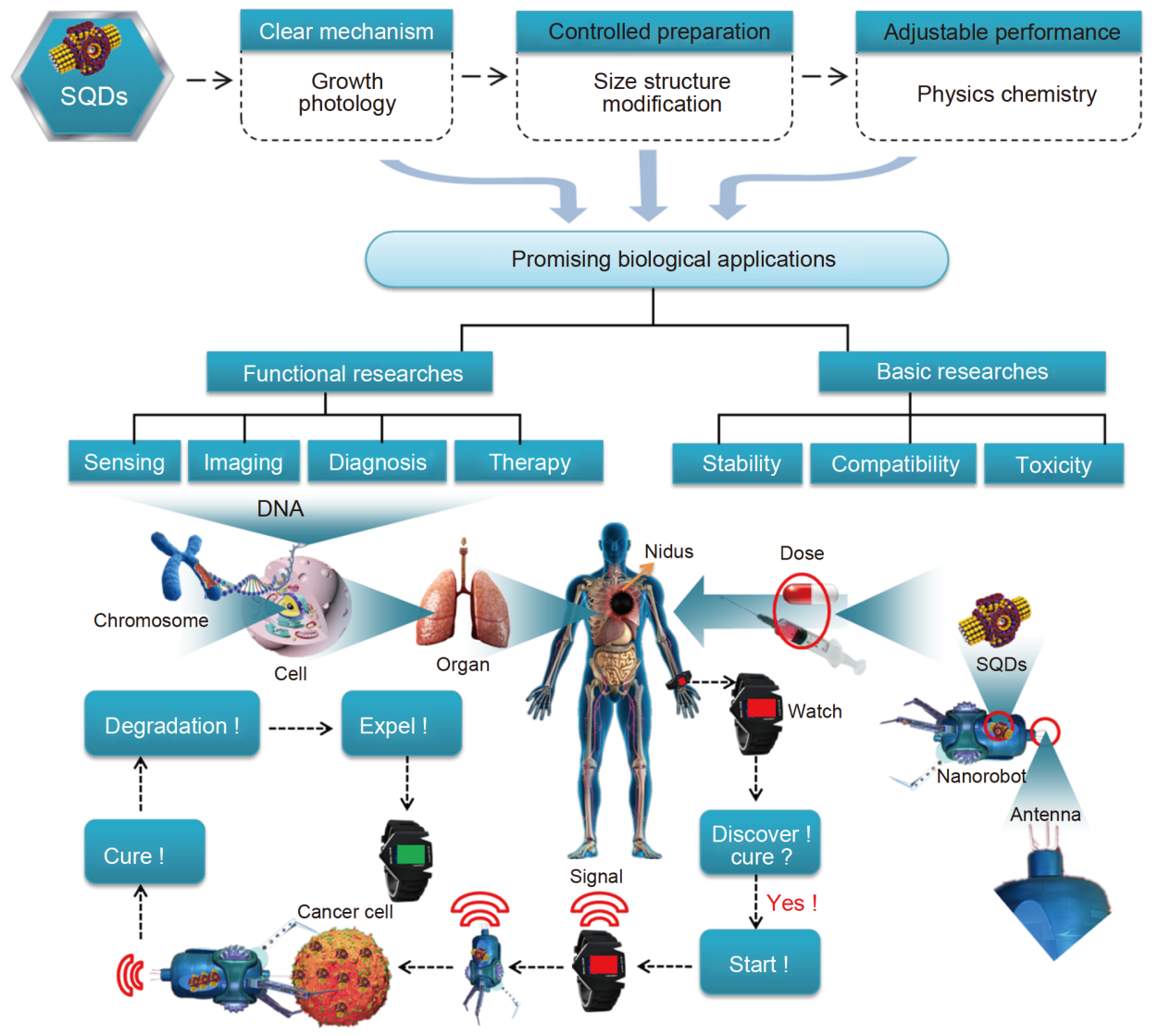

Figure 6 Prospect of biological researches on SQDs. 
Although some clinical prospects cannot be realized in a short time, they still provide a specific direction for the future development of SQDs in the biomedical fields. SQD materials are expected to perform better in the cross-disciplinary field of nanobiomedicine in the future.

\section{Received 6 February 2020; accepted 3 April 2020; published online 12 June 2020}

1 Woggon U. Optical Properties of Semiconductor Quantum Dots. Berlin: Springer, 1997

2 Frasco MF, Chaniotakis N. Semiconductor quantum dots in chemical sensors and biosensors. Sensors, 2009, 9: 7266-7286

3 Bhattacharya P, Pang LY. Semiconductor Optoelectronic Devices. Upper Saddle River: Prentice Hall, 1997

4 Weng J, Ren J. Luminescent quantum dots: A very attractive and promising tool in biomedicine. Curr Med Chem, 2006, 13: 897909

5 Li X, Rui M, Song J, et al. Carbon and graphene quantum dots for optoelectronic and energy devices: A review. Adv Funct Mater, 2015, 25: 4929-4947

6 Pan D, Wang Q, Jiang S, et al. Low-temperature synthesis of oilsoluble CdSe, CdS, and CdSe/CdS core-shell nanocrystals by using various water-soluble anion precursors. J Phys Chem C, 2007, 111: 5661-5666

7 Liu L, Guo X, Li Y, et al. Bifunctional multidentate ligand modified highly stable water-soluble quantum dots. Inorg Chem, 2010, 49: 3768-3775

8 Chen N, He Y, Su Y, et al. The cytotoxicity of cadmium-based quantum dots. Biomaterials, 2012, 33: 1238-1244

9 Cheng X, Lowe SB, Reece PJ, et al. Colloidal silicon quantum dots: From preparation to the modification of self-assembled monolayers (SAMs) for bio-applications. Chem Soc Rev, 2014, 43: $2680-2700$

10 Gui R, Jin $\mathrm{H}$, Wang $\mathrm{Z}$, et al. Black phosphorus quantum dots: Synthesis, properties, functionalized modification and applications. Chem Soc Rev, 2018, 47: 6795-6823

11 Xing C, Chen S, Qiu M, et al. Conceptually novel black phosphorus/cellulose hydrogels as promising photothermal agents for effective cancer therapy. Adv Healthcare Mater, 2018, 7: 1701510

12 Luo M, Fan T, Zhou Y, et al. 2D black phosphorus-based biomedical applications. Adv Funct Mater, 2019, 29: 1808306

13 Reed MA. Quantum dots. Sci Am, 1993, 268: 118-123

14 Xing X, Wang D, Chen Z, et al. ZnTe quantum dots as fluorescence sensors for the detection of iron ions. J Mater Sci-Mater Electron, 2018, 29: 14192-14199

15 Guidelli EJ, Lignos I, Yoo JJ, et al. Mechanistic insights and controlled synthesis of radioluminescent $\mathrm{ZnSe}$ quantum dots using a microfluidic reactor. Chem Mater, 2018, 30: 8562-8570

16 Wang Y, Wang $\mathrm{P}, \mathrm{Wu} \mathrm{Y}$, et al. A cathodic "signal-on" photoelectrochemical sensor for $\mathrm{Hg}^{2+}$ detection based on ion-exchange with ZnS quantum dots. Sens Actuat B-Chem, 2018, 254: 910-915

17 Park Y, Yoo R, Park S, et al. Highly sensitive and selective isoprene sensing performance of $\mathrm{ZnO}$ quantum dots for a breath analyzer. Sens Actuat B-Chem, 2019, 290: 258-266

18 Ma Q, Zhang H, Chen J, et al. Reversible regulation of CdTe quantum dots fluorescence intensity based on prussian blue with high anti-fatigue performance. Chem Commun, 2019, 55: 644647
19 Fan XB, Yu S, Wang X, et al. Susceptible surface sulfide regulates catalytic activity of CdSe quantum dots for hydrogen photogeneration. Adv Mater, 2019, 31: 1804872

20 Wang J, Wang $\mathrm{X}$, Tang $\mathrm{H}$, et al. Ultrasensitive electrochemical detection of tumor cells based on multiple layer CdS quantum dots-functionalized polystyrene microspheres and graphene oxide-polyaniline composite. Biosens Bioelectron, 2018, 100: 1-7

21 Tang X, Ackerman MM, Guyot-Sionnest P. Thermal imaging with plasmon resonance enhanced $\mathrm{HgTe}$ colloidal quantum dot photovoltaic devices. ACS Nano, 2018, 12: 7362-7370

22 Mirzai H, Nordin MN, Curry RJ, et al. The room temperature phosphine-free synthesis of near-infrared emitting HgSe quantum dots. J Mater Chem C, 2014, 2: 2107-2111

23 Goswami N, Giri A, Kar S, et al. Protein-directed synthesis of NIR-emitting, tunable $\mathrm{HgS}$ quantum dots and their applications in metal-ion sensing. Small, 2012, 8: 3175-3184

24 Zhou R, Zhao Q, Liu KK, et al. Europium-decorated $\mathrm{ZnO}$ quantum dots as a fluorescent sensor for the detection of an anthrax biomarker. J Mater Chem C, 2017, 5: 1685-1691

25 Gao X, Cui $\mathrm{Y}$, Levenson RM, et al. In vivo cancer targeting and imaging with semiconductor quantum dots. Nat Biotechnol, 2004, 22: 969-976

26 Yuan Q, Hein S, Misra RDK. New generation of chitosanencapsulated $\mathrm{ZnO}$ quantum dots loaded with drug: Synthesis, characterization and in vitro drug delivery response. Acta Biomater, 2010, 6: 2732-2739

27 Lee J, Sundar VC, Heine JR, et al. Full color emission from II-VI semiconductor quantum dot-polymer composites. Adv Mater, 2000, 12: 1102-1105

$28 \mathrm{Xu} \mathrm{C}$, Zhou R, He W, et al. Fast imaging of eccrine latent fingerprints with nontoxic Mn-doped ZnS QDs. Anal Chem, 2014, 86: 3279-3283

29 Freeman R, Finder T, Bahshi L, et al. Functionalized CdSe/ZnS QDs for the detection of nitroaromatic or RDX explosives. Adv Mater, 2012, 24: 6416-6421

30 Gary DC, Terban MW, Billinge SJL, et al. Two-step nucleation and growth of InP quantum dots via magic-sized cluster intermediates. Chem Mater, 2015, 27: 1432-1441

31 Bang E, Choi Y, Cho J, et al. Large-scale synthesis of highly luminescent InP@ZnS quantum dots using elemental phosphorus precursor. Chem Mater, 2017, 29: 4236-4243

32 Chandrasekaran V, Tessier MD, Dupont D, et al. Nearly blinkingfree, high-purity single-photon emission by colloidal InP/ZnSe quantum dots. Nano Lett, 2017, 17: 6104-6109

33 Ren $\mathrm{Z}$, Sun J, Li H, et al. Bilayer PbS quantum dots for highperformance photodetectors. Adv Mater, 2017, 29: 1702055

34 Yan L, Shen X, Zhang Y, et al. Near-infrared light emitting diodes using PbSe quantum dots. RSC Adv, 2015, 5: 54109-54114

35 Davis NJLK, Böhm ML, Tabachnyk M, et al. Multiple-exciton generation in lead selenide nanorod solar cells with external quantum efficiencies exceeding 120\%. Nat Commun, 2015, 6: 8259

36 Sun YP, Zhou B, Lin Y, et al. Quantum-sized carbon dots for bright and colorful photoluminescence. J Am Chem Soc, 2006, 128: 7756-7757

37 Ponomarenko LA, Schedin F, Katsnelson MI, et al. Chaotic dirac billiard in graphene quantum dots. Science, 2008, 320: 356-358

38 Wang $\mathrm{Z}, \mathrm{Mu} \mathrm{H}$, Zhao $\mathrm{C}$, et al. Harmonic mode-locking and wavelength-tunable $Q$-switching operation in the graphene$\mathrm{Bi}_{2} \mathrm{Te}_{3}$ heterostructure saturable absorber-based fiber laser. Opt 
Eng, 2016, 55: 081314

39 Song YF, Zhang H, Zhao LM, et al. Coexistence and interaction of vector and bound vector solitons in a dispersion-managed fiber laser mode locked by graphene. Opt Express, 2016, 24: 1814-1822

40 Ponraj JS, Xu ZQ, Dhanabalan SC, et al. Photonics and optoelectronics of two-dimensional materials beyond graphene. Nanotechnology, 2016, 27: 462001

41 Sun Z, Zhao Y, Li Z, et al. $\mathrm{TiL}_{4}$-coordinated black phosphorus quantum dots as an efficient contrast agent for in vivo photoacoustic imaging of cancer. Small, 2017, 13: 1602896

42 Fan T, Zhou Y, Qiu M, et al. Black phosphorus: A novel nanoplatform with potential in the field of bio-photonic nanomedicine. J Innov Opt Health Sci, 2018, 11: 1830003

43 Zhang X, Xie H, Liu Z, et al. Black phosphorus quantum dots. Angew Chem Int Ed, 2015, 54: 3653-3657

$44 \mathrm{Xu} \mathrm{Y,} \mathrm{Wang} \mathrm{Z,} \mathrm{Guo} \mathrm{Z,} \mathrm{et} \mathrm{al.} \mathrm{Solvothermal} \mathrm{synthesis} \mathrm{and} \mathrm{ultrafast}$ photonics of black phosphorus quantum dots. Adv Opt Mater, 2016, 4: 1223-1229

45 Wang Y, Zhang F, Tang X, et al. All-optical phosphorene phase modulator with enhanced stability under ambient conditions. Laser Photonics Rev, 2018, 12: 1800016

46 Li C, Liu J, Guo Z, et al. Black phosphorus saturable absorber for a diode-pumped passively $Q$-switched $\mathrm{Er}: \mathrm{CaF}_{2}$ mid-infrared laser. Optics Commun, 2018, 406: 158-162

47 Xue T, Liang W, Li Y, et al. Ultrasensitive detection of miRNA with an antimonene-based surface plasmon resonance sensor. Nat Commun, 2019, 10: 28

48 Liu J, Huang H, Zhang F, et al. Bismuth nanosheets as a Qswitcher for a mid-infrared erbium-doped $\mathrm{SrF}_{2}$ laser. Photon Res, 2018, 6: 762-767

49 Lu L, Liang Z, Wu L, et al. Few-layer bismuthene: Sonochemical exfoliation, nonlinear optics and applications for ultrafast photonics with enhanced stability. Laser Photonics Rev, 2018, 12: 1700221

50 Allen PM, Bawendi MG. Ternary I-III-VI quantum dots luminescent in the red to near-infrared. J Am Chem Soc, 2008, 130: 9240-9241

51 Zimmer JP, Kim SW, Ohnishi S, et al. Size series of small indium arsenide-zinc selenide core-shell nanocrystals and their application to in vivo imaging. J Am Chem Soc, 2006, 128: 2526-2527

52 Jara DH, Yoon SJ, Stamplecoskie KG, et al. Size-dependent photovoltaic performance of $\mathrm{CuInS}_{2}$ quantum dot-sensitized solar cells. Chem Mater, 2014, 26: 7221-7228

53 Du CF, You T, Jiang L, et al. Controllable synthesis of ultrasmall $\mathrm{CuInSe}_{2}$ quantum dots for photovoltaic application. RSC Adv, 2014, 4: 33855-33860

54 Panthani MG, Khan TA, Reid DK, et al. In vivo whole animal fluorescence imaging of a microparticle-based oral vaccine containing $\left(\mathrm{CuInSe}_{x} \mathrm{~S}_{2-x}\right) / \mathrm{ZnS}$ core/shell quantum dots. Nano Lett, 2013, 13: 4294-4298

55 Sun W, Yu J, Deng R, et al. Semiconducting polymer dots doped with europium complexes showing ultranarrow emission and long luminescence lifetime for time-gated cellular imaging. Angew Chem Int Ed, 2013, 52: 11294-11297

56 Liu D, Zhang X, Zhao J, et al. An ultrasensitive sensing platform for microRNA-155 based on $\mathrm{H}_{2} \mathrm{O}_{2}$ quenched hydroxide-dependent ECL emission of PFO Pdots. Biosens Bioelectron, 2020, 150: 111872

57 Zhou X, Liang H, Jiang P, et al. Multifunctional phosphorescent conjugated polymer dots for hypoxia imaging and photodynamic therapy of cancer cells. Adv Sci, 2016, 3: 1500155

58 Mohanty B, Ghorbani-Asl M, Kretschmer S, et al. $\mathrm{MoS}_{2}$ quantum dots as efficient catalyst materials for the oxygen evolution reaction. ACS Catal, 2018, 8: 1683-1689

$59 \mathrm{Xu} \mathrm{S}, \mathrm{Li} \mathrm{D}, \mathrm{Wu}$ P. One-pot, facile, and versatile synthesis of monolayer $\mathrm{MoS}_{2} / \mathrm{WS}_{2}$ quantum dots as bioimaging probes and efficient electrocatalysts for hydrogen evolution reaction. Adv Funct Mater, 2015, 25: 1127-1136

60 Zhao M, Chen AY, Huang D, et al. $\mathrm{MoS}_{2}$ quantum dots as new electrochemiluminescence emitters for ultrasensitive bioanalysis of lipopolysaccharide. Anal Chem, 2017, 89: 8335-8342

61 Wang J, Tan X, Pang X, et al. $\mathrm{MoS}_{2}$ quantum dot@polyaniline inorganic-organic nanohybrids for in vivo dual-modal imaging guided synergistic photothermal/radiation therapy. ACS Appl Mater Interfaces, 2016, 8: 24331-24338

62 Yu X, Cai X, Cui H, et al. Fluorine-free preparation of titanium carbide MXene quantum dots with high near-infrared photothermal performances for cancer therapy. Nanoscale, 2017, 9: 17859-17864

63 Guo Z, Zhu X, Wang S, et al. Fluorescent $\mathrm{Ti}_{3} \mathrm{C}_{2}$ MXene quantum dots for an alkaline phosphatase assay and embryonic stem cell identification based on the inner filter effect. Nanoscale, 2018, 10: 19579-19585

64 Xue Q, Zhang $\mathrm{H}$, Zhu M, et al. Photoluminescent $\mathrm{Ti}_{3} \mathrm{C}_{2}$ MXene quantum dots for multicolor cellular imaging. Adv Mater, 2017, 29: 1604847

65 Chen X, Sun X, Xu W, et al. Ratiometric photoluminescence sensing based on $\mathrm{Ti}_{3} \mathrm{C}_{2}$ MXene quantum dots as an intracellular pH sensor. Nanoscale, 2018, 10: 1111-1118

66 Zeng Z, Yan Y, Chen J, et al. Boosting the photocatalytic ability of $\mathrm{Cu}_{2} \mathrm{O}$ nanowires for $\mathrm{CO}_{2}$ conversion by MXene quantum dots. Adv Funct Mater, 2019, 29: 1806500

$67 \mathrm{Lu} \mathrm{S}$, Sui L, Liu Y, et al. White photoluminescent $\mathrm{Ti}_{3} \mathrm{C}_{2}$ MXene quantum dots with two-photon fluorescence. Adv Sci, 2019, 6: 1801470

$68 \mathrm{Xu}$ G, Niu Y, Yang X, et al. Preparation of $\mathrm{Ti}_{3} \mathrm{C}_{2} \mathrm{~T}_{x}$ MXenederived quantum dots with white/blue-emitting photoluminescence and electrochemiluminescence. Adv Opt Mater, 2018, 6: 1800951

69 Song J, Li J, Li X, et al. Quantum dot light-emitting diodes based on inorganic perovskite cesium lead halides $\left(\mathrm{CsPbX}_{3}\right)$. Adv Mater, 2015, 27: 7162-7167

70 Wang H, Kim DH. Perovskite-based photodetectors: Materials and devices. Chem Soc Rev, 2017, 46: 5204-5236

71 Wang Y, Li X, Song J, et al. All-inorganic colloidal perovskite quantum dots: A new class of lasing materials with favorable characteristics. Adv Mater, 2015, 27: 7101-7108

$72 \mathrm{Im} \mathrm{JH}$, Lee CR, Lee JW, et al. 6.5\% efficient perovskite quantumdot-sensitized solar cell. Nanoscale, 2011, 3: 4088-4093

$73 \mathrm{Li} \mathrm{X}, \mathrm{Wu} \mathrm{Y}$, Zhang S, et al. $\mathrm{CsPbX}_{3}$ quantum dots for lighting and displays: Room-temperature synthesis, photoluminescence superiorities, underlying origins and white light-emitting diodes. Adv Funct Mater, 2016, 26: 2435-2445

74 Sun C, Zhang Y, Ruan C, et al. Efficient and stable white LEDs with silica-coated inorganic perovskite quantum dots. Adv Mater, 2016, 28: 10088-10094

75 Li DM, Cheng LY, Zhang YD, et al. Development of $\mathrm{Cu}_{2} \mathrm{~S} /$ carbon composite electrode for $\mathrm{CdS} / \mathrm{CdSe}$ quantum dot sensitized solar cell modules. Sol Energy Mater Sol Cells, 2014, 120: 454-461

76 Chng ELK, Sofer Z, Pumera M. MoS 2 exhibits stronger toxicity 
with increased exfoliation. Nanoscale, 2014, 6: 14412-14418

77 Bentzen EL, Tomlinson ID, Mason J, et al. Surface modification to reduce nonspecific binding of quantum dots in live cell assays. Bioconjugate Chem, 2005, 16: 1488-1494

78 Oh JK. Surface modification of colloidal CdX-based quantum dots for biomedical applications. J Mater Chem, 2010, 20: 84338445

79 Hoshino A, Fujioka K, Oku T, et al. Physicochemical properties and cellular toxicity of nanocrystal quantum dots depend on their surface modification. Nano Lett, 2004, 4: 2163-2169

80 Liu J, Hu R, Liu J, et al. Cytotoxicity assessment of functionalized CdSe, CdTe and InP quantum dots in two human cancer cell models. Mater Sci Eng-C, 2015, 57: 222-231

81 Speranskaya ES, Beloglazova NV, Lenain P, et al. Polymer-coated fluorescent CdSe-based quantum dots for application in immunoassay. Biosens Bioelectron, 2014, 53: 225-231

82 Jin WJ, Costa-Fernández JM, Pereiro R, et al. Surface-modified CdSe quantum dots as luminescent probes for cyanide determination. Anal Chim Acta, 2004, 522: 1-8

83 Guo G, Liu W, Liang J, et al. Probing the cytotoxicity of CdSe quantum dots with surface modification. Mater Lett, 2007, 61: 1641-1644

84 Guo G, Liu W, Liang J, et al. Preparation and characterization of novel CdSe quantum dots modified with poly(D, L-lactide) nanoparticles. Mater Lett, 2006, 60: 2565-2568

85 Tamura K, Takashi N, Akasaka T, et al. Effects of micro/nano particle size on cell function and morphology. KEM, 2003, 254256: 919-922

86 Schwartz DA, Norberg NS, Nguyen QP, et al. Magnetic quantum dots: Synthesis, spectroscopy, and magnetism of $\mathrm{Co}^{2+}$ - and $\mathrm{Ni}^{2+}$-doped $\mathrm{ZnO}$ nanocrystals. J Am Chem Soc, 2003, 125: 1320513218

87 Le Gall C, Brunetti A, Boukari H, et al. Optical stark effect and dressed exciton states in a Mn-doped CdTe quantum dot. Phys Rev Lett, 2011, 107: 057401

88 Xue G, Chao W, Lu N, et al. Aqueous synthesis of Cu-doped ZnSe quantum dots. J Lumin, 2011, 131: 1300-1304

89 Dabbousi BO, Rodriguez-Viejo J, Mikulec FV, et al. (CdSe)ZnS core-shell quantum dots: Synthesis and characterization of a size series of highly luminescent nanocrystallites. J Phys Chem B, 1997, 101: 9463-9475

90 Altintas Y, Quliyeva U, Gungor K, et al. Highly stable, near-unity efficiency atomically flat semiconductor nanocrystals of CdSe/ $\mathrm{ZnS}$ hetero-nanoplatelets enabled by ZnS-shell hot-injection growth. Small, 2019, 15: 1804854

91 Reiss P, Protière M, Li L. Core/shell semiconductor nanocrystals. Small, 2009, 5: 154-168

92 Qiu Z, Shu J, He Y, et al. CdTe/CdSe quantum dot-based fluorescent aptasensor with hemin/G-quadruplex DNzyme for sensitive detection of lysozyme using rolling circle amplification and strand hybridization. Biosens Bioelectron, 2017, 87: 18-24

93 Rai SC, Wang K, Chen J, et al. Enhanced broad band photodetection through piezo-phototronic effect in CdSe/ZnTe core/ shell nanowire array. Adv Electron Mater, 2015, 1: 1400050

94 Lee YL, Lo YS. Highly efficient quantum-dot-sensitized solar cell based on Co-sensitization of CdS/CdSe. Adv Funct Mater, 2009, 19: 604-609

95 Petchsang N, Shapoval L, Vietmeyer F, et al. Low temperature solution-phase growth of $\mathrm{ZnSe}$ and $\mathrm{ZnSe} / \mathrm{CdSe}$ core/shell nanowires. Nanoscale, 2011, 3: 3145-3151
96 Kirchner C, Liedl T, Kudera S, et al. Cytotoxicity of colloidal CdSe and CdSe/ZnS nanoparticles. Nano Lett, 2005, 5: 331-338

97 Moulick A, Milosavljevic V, Vlachova J, et al. Using CdTe/ZnSe core/shell quantum dots to detect DNA and damage to DNA. IJN, 2017, 12: 1277-1291

98 Cirillo M, Aubert T, Gomes R, et al. "Flash" synthesis of CdSe/ CdS core-shell quantum dots. Chem Mater, 2014, 26: 1154-1160

99 Kang X, Yang Y, Huang L, et al. Large-scale synthesis of watersoluble $\mathrm{CuInSe}_{2} / \mathrm{ZnS}$ and $\mathrm{AgInSe}_{2} / \mathrm{ZnS}$ core/shell quantum dots. Green Chem, 2015, 17: 4482-4488

100 Stewart AJ, O'Reilly EJ, Moriarty RD, et al. A cholesterol biosensor based on the NIR electrogenerated-chemiluminescence (ECL) of water-soluble CdSeTe/ZnS quantum dots. Electrochim Acta, 2015, 157: 8-14

101 Gerion D, Pinaud F, Williams SC, et al. Synthesis and properties of biocompatible water-soluble silica-coated $\mathrm{CdSe} / \mathrm{ZnS}$ semiconductor quantum dots. J Phys Chem B, 2001, 105: 8861-8871

102 He H, Li C, Tian Y, et al. Phosphorescent differential sensing of physiological phosphates with lanthanide ions-modified $\mathrm{Mn}$ doped ZnCdS quantum dots. Anal Chem, 2016, 88: 5892-5897

103 Zhang F, Xu L, Zhao Q, et al. Dopamine-modified Mn-doped ZnS quantum dots fluorescence probe for the sensitive detection of tyrosinase in serum samples and living cells imaging. Sens Actuat B-Chem, 2018, 256: 1069-1077

104 Kumagai K, Uematsu T, Torimoto T, et al. Direct surface modification of semiconductor quantum dots with metal-organic frameworks. CrystEngComm, 2019, 21: 5568-5577

105 Ratnesh RK, Mehata MS. Synthesis and optical properties of coremulti-shell CdSe/CdS/ZnS quantum dots: Surface modifications. Opt Mater, 2017, 64: 250-256

106 Wang J, Lu Y, Peng F, et al. Photostable water-dispersible NIRemitting CdTe/CdS/ZnS core-shell-shell quantum dots for highresolution tumor targeting. Biomaterials, 2013, 34: 9509-9518

107 Huang S, Zhu F, Xiao Q, et al. A CdTe/CdS/ZnS core/shell/shell QDs-based "OFF-ON" fluorescent biosensor for sensitive and specific determination of L-ascorbic acid. RSC Adv, 2014, 4: 46751-46761

108 Bünzli JCG, Comby S, Chauvin AS, et al. New opportunities for lanthanide luminescence. J Rare Earths, 2007, 25: 257-274

109 Evangelista RA, Pollak A, Gudgin Templeton EF. Enzymeamplified lanthanide luminescence for enzyme detection in bioanalytical assays. Anal Biochem, 1991, 197: 213-224

110 Cardoso Dos Santos M, Hildebrandt N. Recent developments in lanthanide-to-quantum dot FRET using time-gated fluorescence detection and photon upconversion. TrAC Trends Anal Chem, 2016, 84: 60-71

111 Geißler D, Linden S, Liermann K, et al. Lanthanides and quantum dots as Förster resonance energy transfer agents for diagnostics and cellular imaging. Inorg Chem, 2013, 53: 1824-1838

112 Planelles-Aragó J, Cordoncillo E, Ferreira RAS, et al. Synthesis, characterization and optical studies on lanthanide-doped CdS quantum dots: New insights on CdS $\rightarrow$ lanthanide energy transfer mechanisms. J Mater Chem, 2011, 21: 1162-1170

113 Planelles-Aragó J, Julián-López B, Cordoncillo E, et al. Lanthanide doped $\mathrm{ZnS}$ quantum dots dispersed in silica glasses: An easy one pot sol-gel synthesis for obtaining novel photonic materials. J Mater Chem, 2008, 18: 5193

114 Charbonnière LJ, Hildebrandt N, Ziessel RF, et al. Lanthanides to quantum dots resonance energy transfer in time-resolved fluoroimmunoassays and luminescence microscopy. J Am Chem Soc, 
2006, 128: 12800-12809

115 Xue $\mathrm{M}$, Wang $\mathrm{X}$, Wang $\mathrm{H}$, et al. The preparation of glutathionecapped CdTe quantum dots and their use in imaging of cells. Talanta, 2011, 83: 1680-1686

116 Kong Y, Chen J, Gao F, et al. A multifunctional ribonuclease-Aconjugated CdTe quantum dot cluster nanosystem for synchronous cancer imaging and therapy. Small, 2010, 6: 2367-2373

117 Xuan T, Wang S, Wang X, et al. Single-step noninjection synthesis of highly luminescent water soluble $\mathrm{Cu}^{+}$doped $\mathrm{CdS}$ quantum dots: Application as bio-imaging agents. Chem Commun, 2013, 49: 9045-9047

$118 \mathrm{Hu}$ D, Zhang P, Gong P, et al. A fast synthesis of near-infrared emitting CdTe/CdSe quantum dots with small hydrodynamic diameter for in vivo imaging probes. Nanoscale, 2011, 3: 47244732

119 Bao Y, Li J, Wang Y, et al. Preparation of water soluble CdSe and $\mathrm{CdSe} / \mathrm{CdS}$ quantum dots and their uses in imaging of cell and blood capillary. Opt Mater, 2012, 34: 1588-1592

120 Zhang Y, Liu JM, Yan XP. Self-assembly of folate onto polyethyleneimine-coated CdS/ZnS quantum dots for targeted turnon fluorescence imaging of folate receptor overexpressed cancer cells. Anal Chem, 2012, 85: 228-234

121 Li C, Ji Y, Wang C, et al. BRCAA1 antibody- and Her2 antibodyconjugated amphiphilic polymer engineered $\mathrm{CdSe} / \mathrm{ZnS}$ quantum dots for targeted imaging of gastric cancer. Nanoscale Res Lett, 2014, 9: 244

122 Law WC, Yong KT, Roy I, et al. Aqueous-phase synthesis of highly luminescent $\mathrm{CdTe} / \mathrm{ZnTe}$ core/shell quantum dots optimized for targeted bioimaging. Small, 2009, 5: 1302-1310

123 Shu C, Huang B, Chen X, et al. Facile synthesis and characterization of water soluble $\mathrm{ZnSe} / \mathrm{ZnS}$ quantum dots for cellar imaging. Spectrochim Acta Part A-Mol Biomol Spectr, 2013, 104: 143-149

124 Bwatanglang IB, Mohammad F, Yusof NA, et al. Folic acid targeted Mn:ZnS quantum dots for theranostic applications of cancer cell imaging and therapy. IJN, 2016, 11: 413

125 Geszke M, Murias M, Balan L, et al. Folic acid-conjugated core/ shell $\mathrm{ZnS}: \mathrm{Mn} / \mathrm{ZnS}$ quantum dots as targeted probes for two photon fluorescence imaging of cancer cells. Acta Biomater, 2011, 7: $1327-1338$

126 Deng D, Qu L, Gu Y. Near-infrared broadly emissive AgInSe ${ }_{2} /$ $\mathrm{ZnS}$ quantum dots for biomedical optical imaging. J Mater Chem C, 2014, 2: 7077-7085

127 Guo W, Chen N, Dong C, et al. One-pot synthesis of hydrophilic $\mathrm{ZnCuInS} / \mathrm{ZnS}$ quantum dots for in vivo imaging. RSC Adv, 2013, 3: 9470-9475

128 Yang W, Guo W, Gong X, et al. Facile synthesis of Gd-Cu-In-S/ $\mathrm{ZnS}$ bimodal quantum dots with optimized properties for tumor targeted fluorescence/MR in vivo imaging. ACS Appl Mater Interfaces, 2015, 7: 18759-18768

129 Taniguchi S, Green M, Rizvi SB, et al. The one-pot synthesis of core/shell/shell CdTe/CdSe/ZnSe quantum dots in aqueous media for in vivo deep tissue imaging. J Mater Chem, 2011, 21: 28772882

130 Pons T, Lequeux N, Mahler B, et al. Synthesis of near-infraredemitting, water-soluble CdTeSe/CdZnS core/shell quantum dots. Chem Mater, 2009, 21: 1418-1424

131 Liu Y, Ai K, Yuan Q, et al. Fluorescence-enhanced gadoliniumdoped zinc oxide quantum dots for magnetic resonance and fluorescence imaging. Biomaterials, 2011, 32: 1185-1192
132 Rosenthal SJ, Chang JC, Kovtun O, et al. Biocompatible quantum dots for biological applications. Chem Biol, 2011, 18: 10-24

133 Wang K, Ruan J, Qian Q, et al. BRCAA1 monoclonal antibody conjugated fluorescent magnetic nanoparticles for in vivo targeted magnetofluorescent imaging of gastric cancer. J Nanobiotechnol, 2011, 9: 23

134 Gravalos C, Jimeno A. Her2 in gastric cancer: A new prognostic factor and a novel therapeutic target. Ann Oncology, 2008, 19: 1523-1529

135 Tiwari DK, Tanaka SI, Inouye Y, et al. Synthesis and characterization of Anti-Her2 antibody conjugated CdSe/CdZnS quantum dots for fluorescence imaging of breast cancer cells. Sensors, 2009, 9: 9332-9354

136 Agostinis P, Berg K, Cengel KA, et al. Photodynamic therapy of cancer: An update. CA-A Cancer J Clinicians, 2011, 61: 250-281

137 Gao G, Jiang YW, Sun W, et al. Fluorescent quantum dots for microbial imaging. Chin Chem Lett, 2018, 29: 1475-1485

138 Lin TY, Lian ZJ, Yao CX, et al. CdSe quantum dots labeled Staphylococcus aureus for research studies of THP-1 derived macrophage phagocytic behavior. RSC Adv, 2020, 10: 260-270

139 Mir IA, Radhakrishanan VS, Rawat K, et al. Bandgap tunable AgInS based quantum dots for high contrast cell imaging with enhanced photodynamic and antifungal applications. Sci Rep, 2018, 8: 9322

140 Hong ZY, Lv C, Liu AA, et al. Clicking hydrazine and aldehyde: The way to labeling of viruses with quantum dots. ACS Nano, 2015, 9: 11750-11760

141 Cai X, Luo Y, Zhang W, et al. pH-sensitive ZnO quantum dotsdoxorubicin nanoparticles for lung cancer targeted drug delivery. ACS Appl Mater Interfaces, 2016, 8: 22442-22450

142 Oliveira E, Santos HM, Jorge S, et al. Sustainable synthesis of luminescent CdTe quantum dots coated with modified silica mesoporous nanoparticles: Towards new protein scavengers and smart drug delivery carriers. Dyes Pigments, 2019, 161: 360-369

143 Chen D, Chen B, Yao F. Doxorubicin-loaded PEG-CdTe quantum dots as a smart drug delivery system for extramedullary multiple myeloma treatment. Nanoscale Res Lett, 2018, 13: 373

144 Yang X, Zhang W, Zhao Z, et al. Quercetin loading CdSe/ZnS nanoparticles as efficient antibacterial and anticancer materials. J InOrg Biochem, 2017, 167: 36-48

145 Han H, Valdepérez D, Jin Q, et al. Dual enzymatic reactionassisted gemcitabine delivery systems for programmed pancreatic cancer therapy. ACS Nano, 2017, 11: 1281-1291

146 Zhang ZY, Xu YD, Ma YY, et al. Biodegradable ZnO@polymer core-shell nanocarriers: $\mathrm{pH}$-triggered release of doxorubicin in vitro. Angew Chem Int Ed, 2013, 52: 4127-4131

147 Chen T, Zhao T, Wei D, et al. Core-shell nanocarriers with ZnO quantum dots-conjugated $\mathrm{Au}$ nanoparticle for tumor-targeted drug delivery. Carbohydrate Polyms, 2013, 92: 1124-1132

148 Birma Bwatanglang I, Mohammad F, Yusof NA, et al. Histological analysis of anti-cancer drug loaded, targeted $\mathrm{Mn}: \mathrm{ZnS}$ quantum dots in metastatic lesions of $4 \mathrm{~T} 1$ challenged mice. J Mater Sci-Mater Med, 2017, 28: 138

149 Zhao T, Liu X, Li Y, et al. Fluorescence and drug loading properties of $\mathrm{ZnSe}: \mathrm{Mn} / \mathrm{ZnS}$-paclitaxel $/ \mathrm{SiO}_{2}$ nanocapsules templated by F127 micelles. J Colloid Interface Sci, 2017, 490: 436-443

150 Zhao MX, Zhu BJ, Yao WJ, et al. The delivery of doxorubicin of multifunctional $\beta$-cyclodextrin-modified $\mathrm{CdSe} / \mathrm{ZnS}$ quantum dots for bioactivity and nano-probing. Chem Biol Drug Des, 2018, 91: 285-293 
151 Hsu JC, Huang CC, Ou KL, et al. Silica nanohybrids integrated with $\mathrm{CuInS}_{2} / \mathrm{ZnS}$ quantum dots and magnetite nanocrystals: Multifunctional agents for dual-modality imaging and drug delivery. J Mater Chem, 2011, 21: 19257-19266

152 Peng $\mathrm{H}$, Cui B, Li G, et al. A multifunctional $\beta$-CD-modified $\mathrm{Fe}_{3} \mathrm{O}_{4} @ \mathrm{ZnO}: \mathrm{Er}^{3+}, \mathrm{Yb}^{3+}$ nanocarrier for antitumor drug delivery and microwave-triggered drug release. Mater Sci Eng-C, 2015, 46: 253-263

153 Yuan Q, Venkatasubramanian R, Hein S, et al. A stimulus-responsive magnetic nanoparticle drug carrier: Magnetite encapsulated by chitosan-grafted-copolymer. Acta Biomater, 2008, 4: 1024-1037

154 Solarska-Ściuk K, Gajewska A, Skolimowski J, et al. Stimulation of production of reactive oxygen and nitrogen species in endothelial cells by unmodified and Fenton-modified ultradisperse detonation diamond. Biotech Appl Biochem, 2013, 60: 259-265

155 Giandomenico CM, Abrams MJ, Murrer BA, et al. Carboxylation of kinetically inert platinum (IV) hydroxy complexes. An Entrée into orally active platinum (IV) antitumor agents. Inorg Chem, 1995, 34: 1015-1021

156 Wong CSM. The trophic effect of dietary fibre is not associated with a change in total crypt number in the distal colon of rats. Carcinogenesis, 2003, 9: 343-348

157 Singhal SS, Wickramarachchi D, Singhal J, et al. Determinants of differential doxorubicin sensitivity between SCLC and NSCLC. FEBS Lett, 2006, 580: 2258-2264

158 Nielsen P, Gyrd-hansen N. Bioavailability of penicillin V after oral administration to fed and fasted pigs. J Vet Pharmacol Ther, 1994, 45: 160-162

159 Liu X, Chen C. Mxene enhanced the photocatalytic activity of ZnO nanorods under visible light. Mater Lett, 2020, 261: 127127

160 Tie L, Yang S, Yu C, et al. In situ decoration of ZnS nanoparticles with $\mathrm{Ti}_{3} \mathrm{C}_{2}$ Mxene nanosheets for efficient photocatalytic hydrogen evolution. J Colloid Interface Sci, 2019, 545: 63-70

161 Li Q, Cen Y, Huang J, et al. Zinc oxide-black phosphorus composites for ultrasensitive nitrogen dioxide sensing. Nanoscale Horiz, 2018, 3: 525-531

Acknowledgements This work was supported by the National Natural Science Foundation of China (61875138, 61435010 and 6181101252), the Science and Technology Innovation Commission of Shenzhen (KQTD2015032416270385, JCYJ20150625103619275 and JCYJ20170811093453105), and China Postdoctoral Science Foundation (2019M663062). The authors also acknowledge the support from the Instrumental Analysis Center of Shenzhen University (Xili Campus).

Author contributions Wang L is responsible for designing the writing framework and full-text writing. Xu D and Gao J are responsible for the literature search and organization of the third part. Duo Y is responsible for the literature search and arrangement of the fourth part. Chen $\mathrm{X}$ and Zhang $\mathrm{H}$ are responsible for the review of the full text.

Conflict of interest The authors declare that they have no conflict of interest.

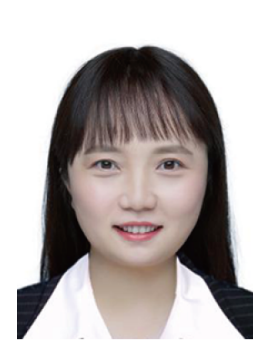

Lude Wang received her $\mathrm{PhD}$ degree from the Southeast University. Currently, she works as a postdoctoral researcher at the International Collaborative Laboratory of $2 \mathrm{D}$ Materials for Optoelectronics Science and Technology of Ministry of Education, Institute of Microscale Optoelectronics, Shenzhen University, China. Her research interests focus on functional materials and their applications in the fields of biomedical science and sensing.

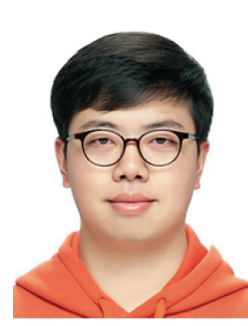

Xiang Chen got his $\mathrm{PhD}$ degree from the University of Science and Technology Beijing. Then, he worked as a research professor in the School of Electrical and Electronic Engineering, Yonsei University. In 2018, he joined the School of Materials Science and Engineering, Nanjing University of Science and Technology (NJUST), as a professor. His research interests are the controllable and wafer-scale synthesis of $2 \mathrm{D}$ semiconducting materials and their applications in integrated, flexible, and bioabsorbable electronics.

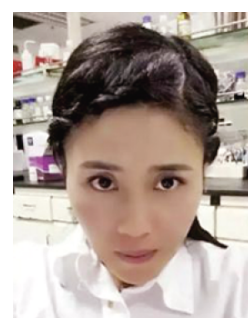

Yanhong Duo received her PhD degree from the Department of Life Sciences at Lanzhou University and the Department of Division of Life and Health Sciences at Tsinghua University in 2017 (Joint training). Currently she is a postdoctoral in the Department of Microbiology, Tumor and Cell Biology, Karolinska Institute. Her current research interests focus on $2 \mathrm{D} \mathrm{ma-}$ terial-based theranostic nanoplatforms for biomedical applications.

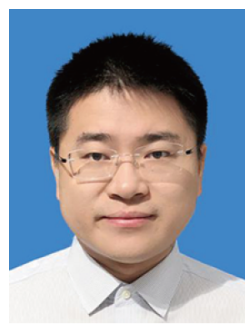

Han Zhang is a full Professor and Director of Shenzhen Engineering Laboratory of Phosphorene and Optoelectronics, Shenzhen University. He is an expert on low-dimensional optoelectronic devices and applications. Most of his publications are correlated to the photonic and optoelectronic applications of 2D nanomaterials especially graphene, transition metal dichalcogenides and black phosphorus. He has been awarded as highly cited researcher by Clarivate Analytics at 2018 and 2019, and OSA fellow.

\section{半导体量子点: 修饰及其在生物医学中的应用}

王路得, 许多 ${ }^{2}$, 高洁 ${ }^{2}$, 陈翔 $2^{2^{*}}$, 杂燕红 ${ }^{1,3^{*}}$, 张晗 ${ }^{1^{*}}$

摘要 半导体量子点由于其高量子产率、可调谐的发射光谱和优 异的光稳定性而受到人们的广泛关注. 这些独特的光学特性赋予 半导体量子点在生物医学领域中出色的应用前景, 譬如量子点可 在生物医学成像、药物输送、临床诊断、光动力疗法、DNA杂交 和RNA分析等领域中得以应用. 本综述介绍了量子点的分类, 并简 要描述了每类量子点的特征. 以II B-VI A型量子点为例, 分别讨论 和总结了其无机和有机修饰方法及相应的优缺点. 基于可控的修 饰方法, 量子点在生物成像和药物传递领域表现出不同的功能. 本 文还列出了量子点的一些典型或经典实例, 用于介绍半导体量子 点在生物医学领域中的应用亮点. 以此为基础, 本综述提出了半导 体量子点在未来生物医学领域中的各种潜在挑战和应用前景. 